\title{
The effect of Dauphiné twinning on plastic strain in quartz
}

\author{
Luca Menegon • Sandra Piazolo • Giorgio Pennacchioni
}

Received: 19 January 2010/Accepted: 29 June 2010/Published online: 24 July 2010

(c) The Author(s) 2010. This article is published with open access at Springerlink.com

\begin{abstract}
We present an electron backscatter diffraction analysis of five quartz porphyroclasts in a greenschist facies $\left(T=300-400^{\circ} \mathrm{C}\right)$ granitoid protomylonite from the Arolla unit of the NW Alps. Mechanical Dauphiné twinning developed pervasively during the incipient stage of deformation within two porphyroclasts oriented with a negative rhomb plane $\{\mathrm{z}\}$ almost orthogonal to the compression direction ( $z$-twin orientation). Twinning was driven by the anisotropy in the elastic compliance of quartz and resulted in the alignment of the poles of the planes of the more compliant positive rhomb $\{\mathrm{r}\}$ nearly parallel to the compression direction ( $r$-twin orientation). In contrast, we report the lack of twinning in two porphyroclasts already oriented with one of the $\{r\}$ planes orthogonal to the compression direction. One twinned porphyroclast has been investigated with more detail. It shows the localization of much of the plastic strain into discrete $r$-twins as a consequence of the higher amount of elastic strain energy stored by $r$-twins in comparison to
\end{abstract}

Communicated by T. L. Grove.

Electronic supplementary material The online version of this article (doi:10.1007/s00410-010-0554-7) contains supplementary material, which is available to authorized users.

\section{Menegon $(\bowtie)$}

Institutt for Geologi, Universitetet i Troms $\varnothing$,

Dramsveien 201, 9037 Troms $\varnothing$, Norway

e-mail: luca.menegon@uit.no

S. Piazolo

Department of Geological Sciences, Stockholm University, Stockholm, Sweden

G. Pennacchioni

Dipartimento di Geoscienze, Università degli Studi di Padova,

Via Giotto 1, 35137 Padova, Italy $z$-twins. The presence of Dauphiné twins induced a switch in the dominant active slip systems during plastic deformation, from basal $<\mathrm{a}>$ (regions without twinning) to $\{\pi\}$ and $\left\{\pi^{\prime}\right\}$ $<a>$ (pervasively twinned regions). Dynamic recrystallization is localized along an $r$-twin and occurred dominantly by progressive subgrain rotation, with a local component of bulging recrystallization. Part of the recrystallized grains underwent rigid-body rotation, approximately about the bulk vorticity axis, which accounts for the development of large misorientation angles. The recrystallized grain size piezometer for quartz yields differential stress of $100 \mathrm{MPa}$. The comparison of this palaeostress estimate with literature data suggests that mechanical Dauphiné twinning could have a potential use as palaeopiezometer in quartz-bearing rocks.

Keywords Dauphiné twinning - Quartz · Electron backscatter diffraction (EBSD) .

Slip systems $\cdot$ Subgrains $\cdot$ Recrystallization

\section{Introduction}

Dauphiné twinning in trigonal $\alpha$-quartz consists of a $60^{\circ}$ rotation around the $c$-axis resulting in a reversal of the crystallographic positive and negative forms (Frondel 1962). As a consequence, Dauphiné twins cannot be detected by standard optical microscopy. Before the advent of electron backscatter diffraction (EBSD; e.g. Adams et al. 1992), Dauphiné twinning could only be recognized via $\mathrm{X}$-ray diffraction techniques from the interpretation of pole figures and inverse pole figures. More recently, EBSD has allowed the recognition of Dauphiné twins in quartzbearing metamorphic rocks (e.g. Lloyd and Freeman 1994; Trimby et al. 1998; Heidelbach et al. 2000; Lloyd 2000, 2004; Neumann 2000; Trepmann and Stöckhert 2003; 
Piazolo et al. 2005; Stipp and Kunze 2008) deformed in a range of geological conditions from diagenetic (Mørk and Moen 2007) to amphibolite facies metamorphism (Lloyd 2004). By integrating EBSD analyses with TEM studies and X-ray and neutron diffraction data, it is currently possible to investigate Dauphiné twinning in detail and to clarify some aspects of its significance in naturally and experimentally deformed rocks.

Despite the increasing evidence of Dauphiné twinning in deformed metamorphic rocks, the possible relationships between twinning and deformation conditions are poorly constrained. It is well known that Dauphiné twinning in quartz cannot accommodate permanent shear strain and, therefore, it cannot be considered as a deformation mechanism (Tullis 1970). However, quartz can undergo mechanical Dauphiné twinning when subjected to high stress (e.g. Thomas and Wooster 1951), as result of shock deformation (Wenk et al. 2005), and also at lower stresses typical of tectonic deformation as observed in experiments (Tullis 1970) and in natural tectonites (Pehl and Wenk 2005). In addition to mechanical origin, Dauphiné twins occur at the $\alpha-\beta$ quartz transition and as growth twins (e.g. Piazolo et al. 2005). In the last decades, several compression experiments on polycrystalline quartz shed light on the thermodynamics of twinning, on its mechanism of formation and on its dependence on temperature and stress conditions (Tullis 1970; Tullis and Tullis 1972; Wenk et al. 2006, 2007). Accordingly, it is generally accepted that mechanical Dauphiné twinning is a stress-dependent feature related to the crystallographic orientation of quartz with respect to the stress field and that it acts to maximize the elastic strain energy of the crystal under constant stress conditions as part of the process of minimization of the internal energy of the system (Tullis and Tullis 1972). However, given that Dauphiné twinning does not act as a deformation mechanism, little attention has been dedicated to its possible role on the microstructural evolution in plastically sheared quartz-bearing rocks.

Recent contributions re-evaluated the potential use of Dauphiné twinning in natural tectonites as a source of information on deformation conditions. Pehl and Wenk (2005) suggested that twinning can be used as palaeopiezometer in quartz-bearing rocks, and Wenk et al. (2006) further discussed this issue after a suite of deformation experiments on fine-grained novaculite performed at varying temperatures and differential stresses. Lloyd (2004) showed that Dauphiné twinning extensively concurred in the progressive grain size reduction in quartz accompanying the mylonitization of a quartz vein and that it contributed to the formation of both new grain and subgrain boundaries. Stipp and Kunze (2008) recognized Dauphiné twin bands as preferred sites of dynamic recrystallization in naturally and experimentally deformed quartzites.
The aim of this paper is to investigate the relationships between Dauphiné twinning, deformation conditions and microstructural modifications in quartz grains. Our results show that the presence of Dauphiné twins exerts an important role in the distribution of the intracrystalline plastic deformation in quartz, as well as in the activation of different sets of slip systems. Dauphiné twin bands can be preferred sites for dynamic recrystallization and can provide an explanation of the origin of some intracrystalline shear bands in quartz. The potential use of mechanical Dauphiné twinning as palaeopiezometer is discussed by comparing existing experimental data with palaeostress estimates using recrystallized grain size piezometer of quartz.

\section{Materials and methods}

Sample description

All data presented come from five quartz porphyroclasts in a granitoid protomylonite (porphyroclasts A-E in sample M1G: Fig. 1a). The paper focuses on the analysis of
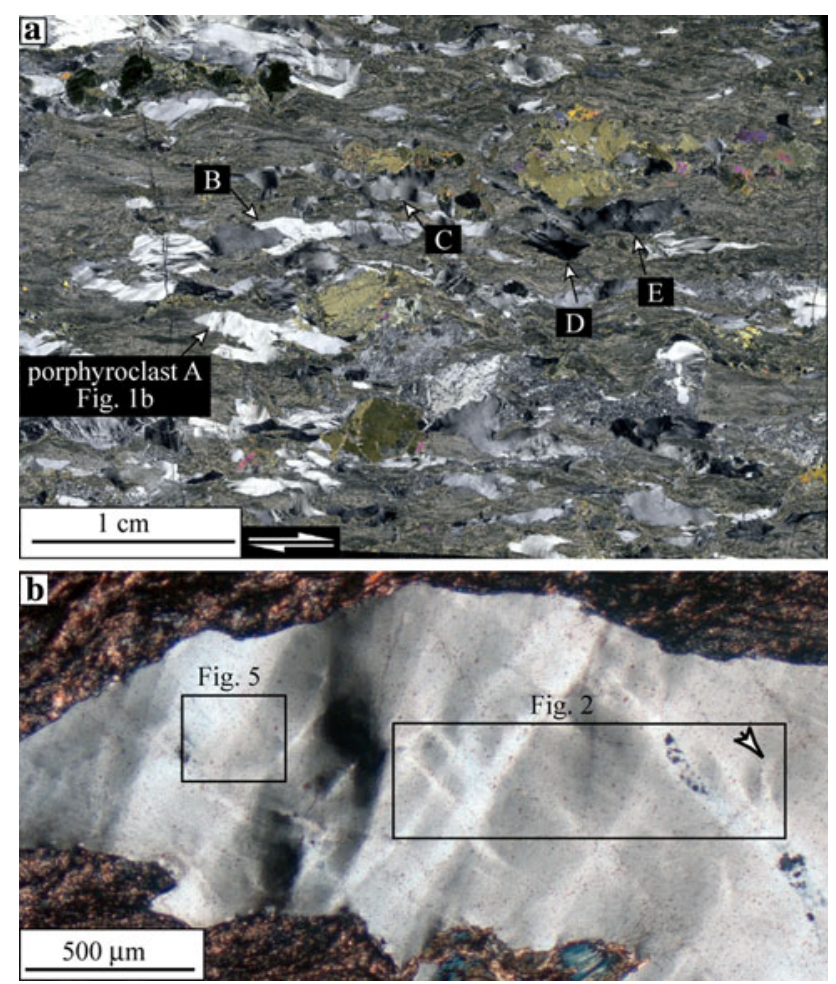

Fig. 1 a Optical micrograph of the granite protomylonite including the studied quartz porphyroclasts A, B, C, D and E. Dextral shear sense. Crossed polarizer. b Optical microstructure of porphyroclast A. Crossed polarizer. Rectangles encompass the areas investigated in detail by EBSD. Arrowhead indicates the optically visible deformation band outlined in the orientation contrast image in Fig. 3c 
Dauphiné twinning microstructures from porphyroclast $\mathrm{A}$. EBSD data collected from porphyroclasts B, C, D and E are included in the electronic supplementary material and discussed in the paper in the light of the main interpretations derived from the analysis of porphyroclast A.

The protomylonite sample comes from the Austroalpine Arolla unit of the Dent Blanche nappe in the North-western Italian Alps (Pennacchioni and Guermani 1993; Dal Piaz et al. 2001). The Arolla unit dominantly consists of mylonites derived from late palaeozoic granitoids during the Alpine orogeny. The synmylonitic mineral assemblage (quartz + albite + chlorite + epidote + muscovite + actinolite \pm stilpnomelane) developed under greenschist facies (300-400 ${ }^{\circ} \mathrm{C}$ : Fitz Gerald and Stünitz 1993) and fluid-present conditions (Pennacchioni and Guermani 1993; Menegon et al. 2008). Kinematic indicators in the mylonites indicate a top-to-NW sense of tectonic transport developed during Alpine thrusting (Pennacchioni and Guermani 1993). Metre- to kilometre-sized low-strain pods of Arolla granitoids escaped strong Alpine tectono-metamorphic overprint and show an undeformed to protomylonitic fabric.

In the studied protomylonite sample, quartz forms 30 volume $\%$ and occurs as elongated porphyroclasts up to $2 \mathrm{~cm}$ in length. Porphyroclasts are dispersed in a foliated mica-rich aggregate derived from the pervasive greenschist facies alteration of magmatic plagioclase (Fig. 1a). This fine-grained aggregate behaved as a weak matrix during shear deformation, whereas quartz, hornblende and Kfeldspar survived as more or less deformed porphyroclasts up to high strain (Pennacchioni and Guermani 1993; Menegon et al. 2008). The rheological contrast between weak and strong phases generally results in strain partitioning during bulk flow, with the non-coaxial and coaxial component of shearing mainly accommodated by the weak matrix and the strong porphyroclasts, respectively (e.g. Lister and Williams 1983; Goodwin and Tikoff 2002). In the Arolla deformed granitoids, a dominant non-coaxial component of shearing is clearly recorded in the finegrained matrix by the asymmetry of many fabric elements (e.g. C- and C'-type shear bands, asymmetric strain shadows around porphyroclasts: Pennacchioni and Guermani 1993). In contrast, quartz is wrapped by the mica-rich foliation and underwent a dominant coaxial deformation as attested by (1) the common presence of internal sets of conjugate shear bands symmetrically arranged with respect to the normal to the foliation (Z-direction of bulk strain) and (2) the orthorhombic symmetry of the $c$-axis crystallographic preferred orientation, showing a strong maximum about the Z-direction (Menegon et al. 2008). Hence, the Z-direction can be reasonably assumed to be parallel to the maximum compressive axis within quartz porphyroclasts (Menegon et al. 2008).
Electron backscatter diffraction (EBSD) analysis

Crystallographic orientation data were obtained from automatically indexed EBSD patterns collected on a Philips XL-30-ESEM-FEG at the Department of Geological Sciences, Stockholm University. EBSD analysis was carried out on thin sections cut perpendicular to the foliation (XY plane of finite strain) and parallel to the stretching lineation (X-direction). Thin sections were SYTON ${ }^{\circledR}$-polished (Fynn and Powell 1979) before EBSD analysis. Working conditions were as follows: $25 \mathrm{kV}$ accelerating voltage, $\sim 0.8 \mathrm{nA}$ beam current, working distance of about $20 \mathrm{~mm}, \quad 70^{\circ}$ sample tilt and low-vacuum mode (0.3-0.4 torr). EBSD patterns were acquired on rectangular grids by moving the electron beam at a regular step size of 1 or $1.5 \mu \mathrm{m}$. Four EBSD maps collected from porphyroclast $\mathrm{A}$ are presented and discussed in this paper (Fig. 1b), whereas four additional maps, collected from four different porphyroclasts, are presented in the supplementary material.

EBSD patterns were indexed using CHANNEL 5 software from HKL Technology, Oxford Instruments. The overall indexing in the four maps was between 76 and $98 \%$ for trigonal quartz of Laue group $-3 \mathrm{~m}$. Indexing of the four maps included in the electronic supplementary material ranges from 65 to $98 \%$. For the selection of the analysis areas and for further confirmation of the position and shape of Dauphiné twins, high-resolution orientation contrast images were taken (Prior et al. 1996).

\section{Processing and presentation of EBSD data}

Non-indexed solutions were replaced by the most common neighbour orientation to reduce data noise, following the procedure tested by Prior et al. (2002) and Bestmann and Prior (2003). The resulting data are presented in form of pole figures (upper hemisphere, equal angle stereographic projection) and of colour-coded maps. Considering the common slip systems of quartz, the following directions and planes have been plotted: $<0001>$ (c-axis), $<11-20>$ (a-axis), \{10-10\} (prism $\{\mathrm{m}\}$ ), $\{10-11\}$ (positive rhomb $\{\mathrm{r}\}$ ), $\{01-11\}$ (negative rhomb $\{\mathrm{z}\}),\{10-12\}$ (positive acute rhomb $\{\pi\}$ ), $\{01-12\}$ (negative acute rhomb $\left\{\pi^{\prime}\right\}$ ).

We present data in the following map formats: (1) the grey levels band contrast map (BC), which displays the variation in EBSD pattern quality, where darker pixels commonly represent grain or subgrain boundaries (as data at boundaries exhibit lower pattern quality), (2) a map showing the crystal orientation at each data point according to a colour-coded inverse pole figure (IPF), representing the crystal orientation relative to the stretching lineation (X-direction), and (3) the texture component map (TC), which shows the relative misorientation (here up to $30^{\circ}$ ) of 
every analysed point with respect to a chosen reference orientation.

Misorientation angles between crystal orientation of neighbouring data points have been grouped into (1) lowangle boundaries, with misorientation of $2-5^{\circ}$ and $5-10^{\circ}$, represented as yellow and pink lines, respectively, and (2) high-angle boundaries, with misorientation $>10^{\circ}$, represented as black lines. High-angle boundaries between recrystallized grains have been investigated in detail by means of grain boundary misorientation maps, where various ranges of misorientation across high-angle boundaries $\left(10-20^{\circ}, 20-40^{\circ}, 40-60^{\circ}, 60-80^{\circ},>80^{\circ}\right)$ have been highlighted by differently coloured lines. Dauphiné twin boundaries are defined by a $60^{\circ}$ rotation (with an accuracy of $2^{\circ}$ ) of the crystal lattice about the $c$-axis and are represented as red lines. The density of low-angle boundaries is calculated as their cumulative length per map area (in data points).

Crystallographic misorientations have been investigated on misorientation profiles, frequency diagrams of misorientation angles for correlated distributions and misorientation axis/angle pairs. It should be noted that misorientation axes for small misorientation angles $\left(<5^{\circ}\right)$ are poorly constrained (Prior 1999). Among all the combinations of symmetrically equivalent axis/angle pairs, we followed the general convention to select the pair with the minimum misorientation angle (Wheeler et al. 2001).

The analysis of grain size distribution was performed on the recrystallized grains automatically identified by the indexing software when completely surrounded by boundaries with misorientation angles $>10^{\circ}$. The grain size is calculated as the diameter of the circle with an area equivalent to that of the grain.

\section{Boundary trace analysis}

Boundary trace analysis (e.g. Prior et al. 2002; Barrie et al. 2008; Piazolo et al. 2008) is a method for determining the geometry of low-angle boundary and the active slip system(s) from EBSD data. When the 3D orientation of a boundary is unknown, the boundary trace analysis provides a crystallographically consistent solution for the boundary geometry, if ideal tilt and twist boundary models are assumed. This method considers the dispersion of the orientation data around a rotation axis for an area sampled across a selected 2D trace of a low-angle boundary on EBSD maps. The rotation axis is identified on the pole figures as the direction with no or little dispersion (Lloyd and Freeman 1994). In the case of a tilt boundary, the boundary plane must contain the $2 \mathrm{D}$ boundary trace and the rotation axis. A plane at high angle (ideally at $90^{\circ}$ ) to the boundary plane, and containing the rotation axis, represents the most likely active slip plane and must contain the slip direction. In the case of a twist boundary, the rotation axis is orthogonal to the boundary plane. The formation of twist boundaries implies the simultaneous operation of at least two intersecting sets of screw dislocations with different Burger vectors. Therefore, in the case of a twist boundary, the inference of active slip system(s) has to rely upon crystallographic modelling (e.g. Neumann 2000; Lloyd 2004). Possible relationships between active slip systems and misorientation axes for twist boundaries in quartz have been proposed by Lloyd (2004), based on a crystallographic model that takes into account cross-slip systems. In the present study, we used the boundary trace analysis to characterize the nature of low-angle boundaries of porphyroclast $\mathrm{A}$ in regions close to and away from Dauphiné twin boundaries.

\section{Results}

Optical microstructure of porphyroclast A

The porphyroclast A (Fig. 1b) shows (1) undulatory extinction, (2) a pervasive network of conjugate deformation bands, up to $100 \mu \mathrm{m}$ thick, intersecting at angles of $70^{\circ}-90^{\circ}$ in $2 \mathrm{D}$ and symmetrically arranged with respect to the Z-direction, and (3) small pockets of recrystallized grains $(\leq 20 \mu \mathrm{m}$ in size). These latter occur only within one set of the conjugate deformation bands and form about $2 \%$ of the total area of the porphyroclast. A detailed description of the optical microstructure of quartz in the Arolla sheared granitoids can be found in Menegon et al. (2008).

\section{EBSD analysis of porphyroclast A}

\section{Dauphiné twinning microstructures}

In the IPF map (Fig. 2a), the porphyroclast contains extensive domains of blue-violet and green-yellow colour separated by boundaries indexed as Dauphiné twin boundaries for most of their length and therefore identified as Dauphiné twins. The porphyroclast has the $c$-axis oriented approximately in the XZ plane of finite strain and synthetically inclined with the bulk dextral shear sense of $35^{\circ}-45^{\circ}$ to the Z-direction (Fig. 2b). The pole figures (Fig. 2b) show characteristic features indicative for the presence of Dauphiné twins, such as (1) the occurrence of one $c$-axis orientation, but six rather than three pairs of positive $\{r\}$ and negative $\{z\}$ rhombohedral planes, and (2) the preferential alignment of the superposed $\{r\}$ and $\{\mathrm{z}\}$ poles nearly parallel to the maximum compressive axis (Tullis 1970; Tullis and Tullis 1972; Pehl and Wenk 2005), here parallel to Z-direction (Menegon et al. 2008). The presence of 


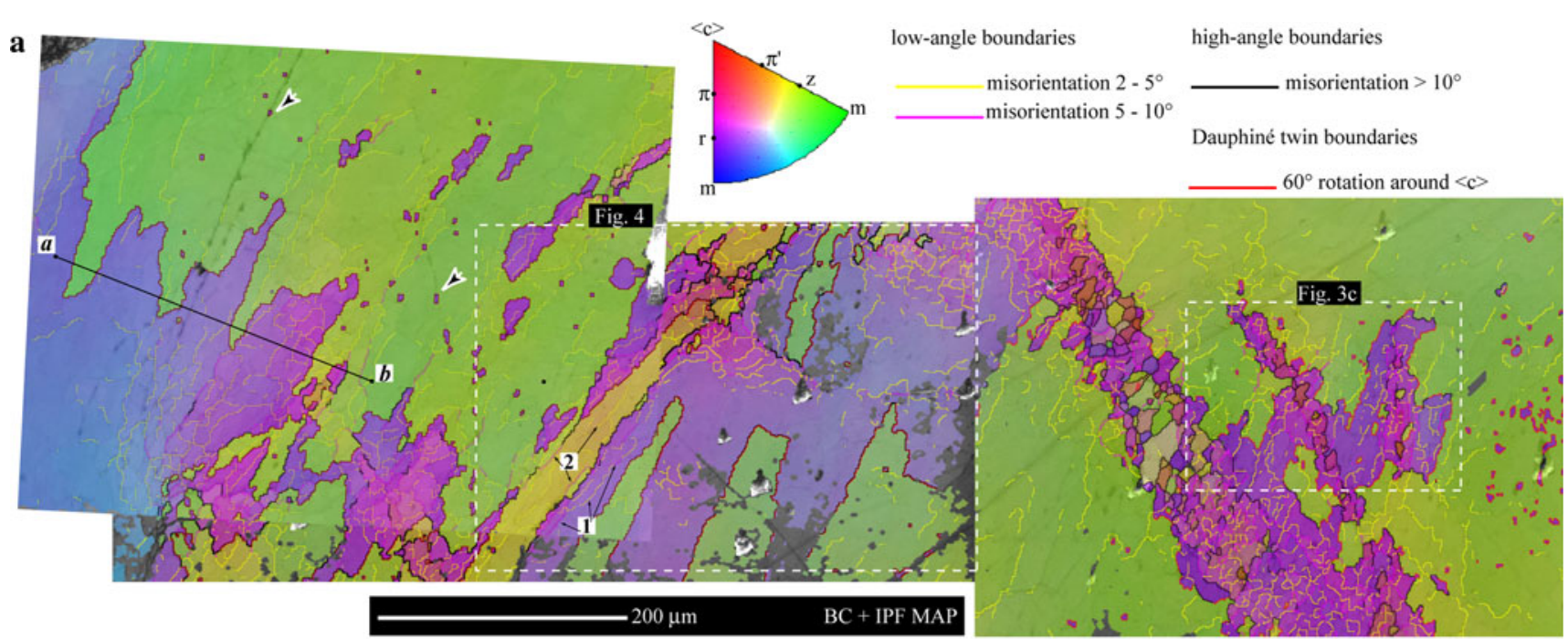

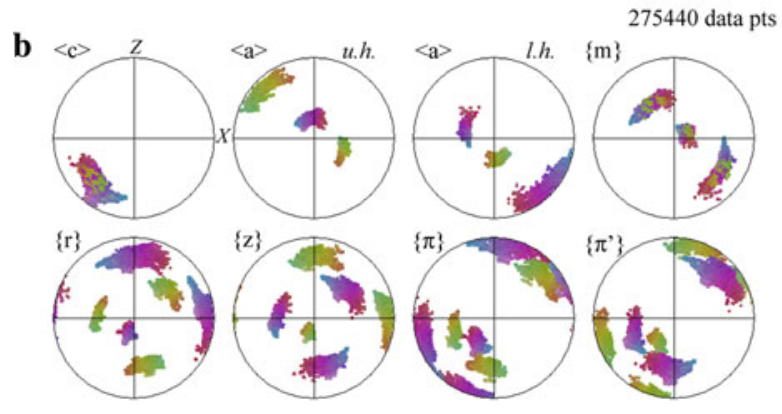

Fig. 2 a Processed EBSD Band Contrast (BC) + Inverse Pole Figure (IPF) map of the Dauphiné twinning microstructure in porphyroclast A (see Fig. 1b). The figure has been obtained from three individual maps resulting in some inaccuracies in the overlapping areas. The map is colour-coded according to the inverse pole figure of quartz. Key to colour code of the different boundary types is shown in the upper right corner. Grey pixels are non-indexed points. $R$-twins and $z$-twins are dominantly violet and green, respectively. Alignments of isolated clusters of data points indexed as Dauphiné twins result from misindexing along cracks (see arrowheads). Black line represents the location of misorientation profile $a-b$ displayed in Fig. 2c. White dashed rectangles represent the location of the orientation contrast

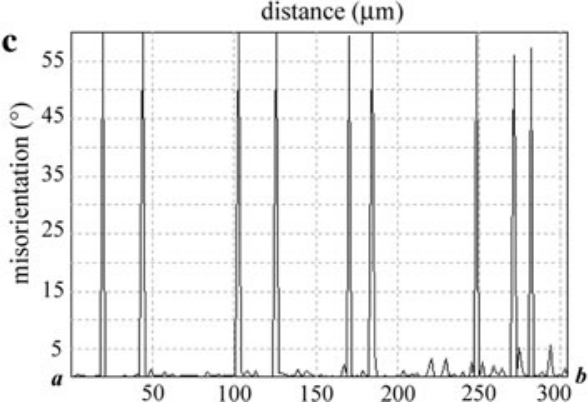

image displayed in Fig. 3c and of the texture component (TC) map shown in Fig. 4. Numbers 1 and 2 refer to examples of low-angle boundaries included in datasets 1 and 2 for boundary trace analysis displayed in Fig. 6. b Pole figures of the crystallographic orientation data of the Dauphiné twinning microstructure. The recrystallized grains have not been included. Colour coding as in Fig. 2a. Upper hemisphere, equal angle stereographic projection. The orientation of the $\langle a\rangle$ axis is plotted on the upper hemisphere (u. h.) and on the lower hemisphere (l. h.) of the stereographic projection. c Misorientation profile $a-b$ showing the change in orientation with respect to the starting point

symmetrically arranged about the Z-direction. The dominant set of twin boundaries is oriented subparallel to the $c$-axis, whereas the shorter one form traces subparallel to the basal planes (Fig. 2a). The outlines of the twins, as identified with EBSD, are confirmed by orientation contrast images (Fig. 3c) and match with many boundaries of the conjugate deformation bands observed under the optical microscope (Figs. 1b, 3c).

\section{Intracrystalline deformation and geometry of low-angle boundaries}

The porphyroclast shows $50-\mu \mathrm{m}$-thick bands with lattice distortion of up to $25^{\circ}-30^{\circ}$. These are spaced $100 \mu \mathrm{m}$ apart and inclined at a clockwise angle of $\sim 45^{\circ}$ to the $\mathrm{Z}$-axis 


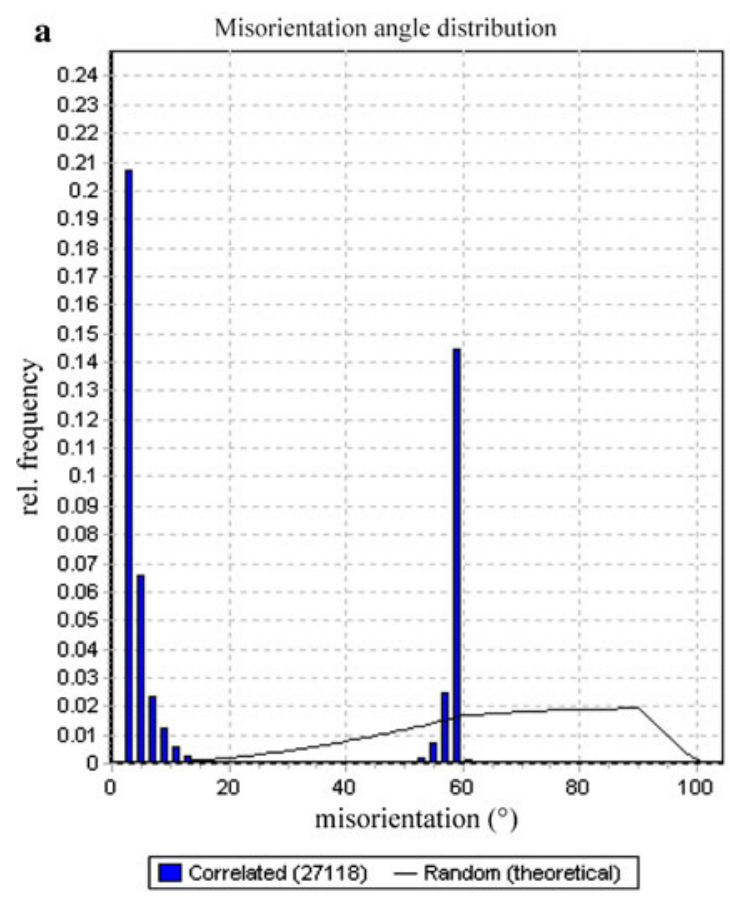

Fig. 3 Histogram of distribution of misorientation angles (a) and misorientation axis/angle pairs (b) for the Dauphiné twinning microstructure of Fig. 2a. The recrystallized grains have not been included. Misorientation axis/angle pairs are displayed in crystal

(i.e. they are left-dipping on the EBSD map) (Figs. 4, 5). These misorientation bands locally flank Dauphiné twin boundaries (Fig. 4) but are particularly well developed within $r$-twins (Fig. 5). Consistently, $r$-twins in general exhibit twice the density of low-angle boundaries than $z$-twins (density of $26 \%$ vs. $13 \%$, respectively), although $r$-twins are also poor in low-angle boundaries over large portions (Fig. 2a).

The 2D trace of the dominant set of low-angle boundaries is oriented with a clockwise angle of $\sim 45^{\circ}$ to the Z-direction within both individual $r$ - and $z$-twins (Figs. 2a, $4,5)$. $R$-twins locally show areas of extensive subgrain polygonization resulting from the occurrence of a set of low-angle boundaries oriented with an anticlockwise angle of $30-45^{\circ}$ to $\mathrm{Z}$ (Fig. 2a). Polygonized areas are nearly absent in the $z$-twins. Low-angle boundaries within the $r$ - and $z$-twins never cut through twin boundaries. Lowangle boundaries subparallel to Z- and X-directions are subordinate and will not be discussed further.

The misorientation angle distribution for most part of the Dauphine twin microstructure is bimodal, with the strongest peak between $5^{\circ}$ and $10^{\circ}$ and a secondary peak between $50^{\circ}$ and $60^{\circ}$ (Fig. 3a). The misorientation frequencies fall to almost zero in the range of $15^{\circ}-50^{\circ}$ and beyond $60^{\circ}$. The rotation axis for misorientations of $5^{\circ}-10^{\circ}$ b
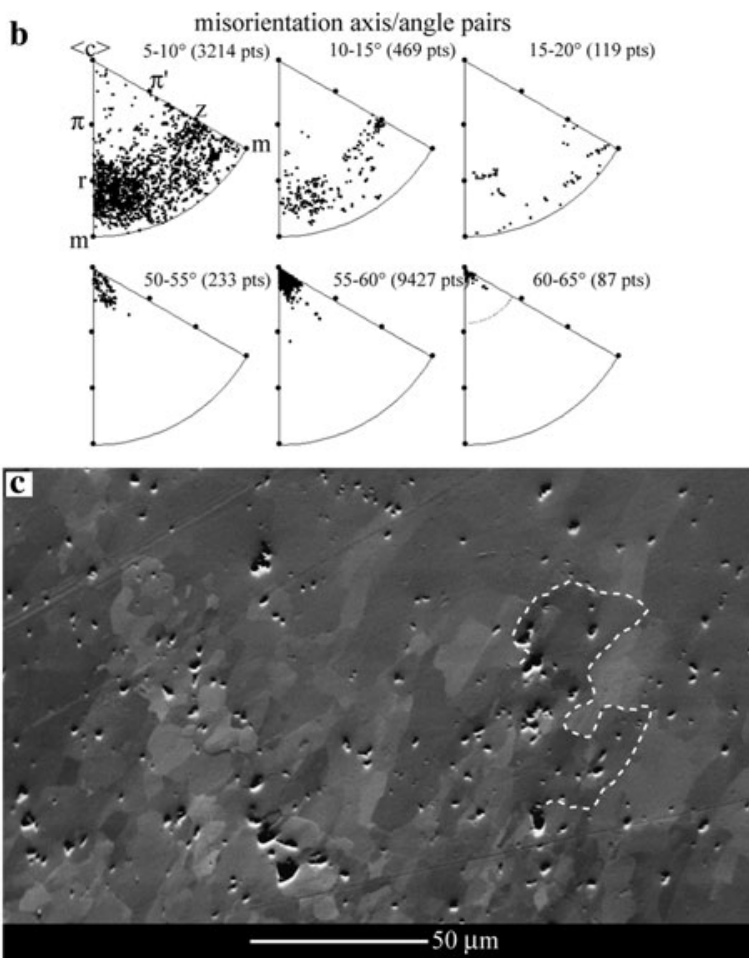

coordinates (inverse pole figure for quartz). c Orientation contrast image of part of the Dauphiné twinning microstructure outlined in Fig. 2a. The white dashed line is an example of one EBSD determined Dauphiné twin boundary

is roughly distributed along a wide girdle connecting the poles to the $\{r\}$ and $\{z\}$ planes, with two major clusters mainly around $\{\mathrm{r}\}$ (dominant) and around $\{\mathrm{z}\}$ (Fig. 3b).

For the interpretation of the slip system associated with the low-angle boundaries, we performed a boundary trace analysis of four representative datasets, each of which is characteristic for a specific microstructure (Fig. 6; Table 1). Each dataset has been sampled within relatively small areas across low-angle boundaries with the same 2D orientation. Datasets 1 and 2 refer to microstructures of the porphyroclast area shown in Figs. 2a and 4, whereas datasets 3 and 4 refer to the area shown in Fig. 5. Dataset 1 represents traces of low-angle boundaries within the $r$-twin oriented with a clockwise angle of $\sim 45^{\circ}$ to the Z-direction and sampled in close proximity to a Dauphiné twin boundary. The dispersion paths on the pole figures identify $\{r\}$ as the rotation axis. A tilt boundary plane containing the boundary trace of the low-angle boundary and the rotation axis is consistent with these data (Fig. 6). Such a tilt boundary can be explained by the activity of the slip system $\left\{\pi^{\prime}\right\}<a>$ (Fig. 6). Dataset 2 represents traces of low-angle boundaries in the $z$-twin oriented with a clockwise angle of $\sim 45^{\circ}$ to the Z-direction and sampled in close proximity to a Dauphiné twin boundary. The rotation axis is $\{z\}$. The boundary trace and rotation axis are consistent 


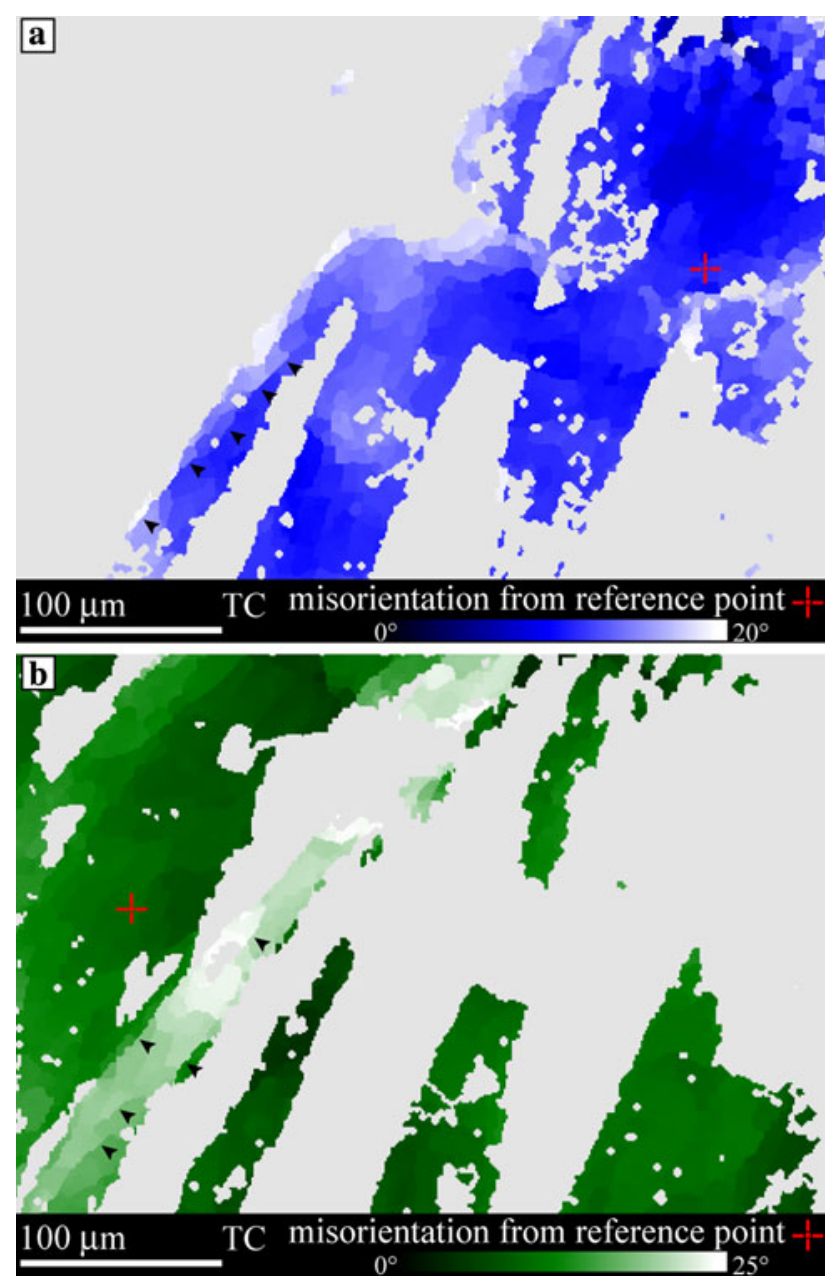

Fig. 4 Processed EBSD Texture Component (TC) maps of part of the $r$-twin (a) and $z$-twin (b) microstructure outlined in Fig. 2a. The maps are colour-shaded according to the angular misorientation from the reference point marked with a red cross. Grey pixels within the colour-shaded portions are non-indexed points (compare with Fig. 2). Grey pixels outside the colour-coded portions are points with a misorientation higher than $20^{\circ}$ (a) and than $25^{\circ}$ (b). The black arrowheads indicate low-angle boundaries from dataset 1 (a) and 2 (b) for boundary trace analysis displayed in Fig. 6

with a tilt boundary with an active $\{\pi\}<\mathrm{a}>$ slip system (Fig. 6).

Most of the map in Fig. 5 shows an $r$-twin, with only a limited occurrence of $z$-twin at the lower right corner. Dataset 3 represents traces of subgrain boundaries oriented with a clockwise angle of $\sim 45^{\circ}$ to the Z-direction within the central left-dipping misorientation band (see Fig. 5 for dataset location), located at about $200 \mu \mathrm{m}$ from the twin boundary. Crystal directions show a clear dispersion about $\{\mathrm{m}\}$. The data are consistent with a tilt boundary and the operation of the slip system basal $<a>$ (Fig. 6). Dataset 4 also represents traces of subgrain boundaries oriented with a clockwise angle of $\sim 45^{\circ}$ to the Z-direction within a misorientation band, but closer (at about $20 \mu \mathrm{m}$ ) to the twin boundary than dataset 3 . The dispersion of the crystal directions occurs about $\{r\}$, and the overall pattern reminds that of dataset 1. Crystallographic relationships for dataset 4 are consistent with a tilt boundary model and with the activity of the slip system $\left\{\pi^{\prime}\right\}<\mathrm{a}>$ (Fig. 6). Consistent with the boundary trace analysis, misorientation axis/angle pair diagrams for datasets 1,2 and for the left-dipping deformation band where dataset 3 was sampled from show clusters of misorientation axis close to $\{r\},\{z\}$ and $\{m\}$, respectively (Fig. 7).

\section{Recrystallized grains}

Incipient dynamic recrystallization is observed in a $\sim 200$ $\mu \mathrm{m}$-long and $<100-\mu \mathrm{m}$-thick band along an $r$-twin parallel to the trace of the basal plane of the host porphyroclast (Fig. 8a). Subgrains, about the same size of recrystallized grains, and recrystallized grains themselves are strictly confined within the discrete $r$-twin band and do not form in the $z$-twin (Figs. 2a, 8a). The $z$-twin shows a higher lattice distortion in close proximity to the band of recrystallized grains than away from it ( $\sim 15^{\circ}$ vs. $\sim 5^{\circ}$, Fig. 8 b). The $r$-twin band in Fig. 8a locally displays sutured grain boundaries in contact with the neighbouring $z$-twin, with bulges of about the same size as subgrains and recrystallized grains within the band.

The pole figures of the recrystallized aggregate (Fig. 8c) show individual maxima tightly overlapping with those of the parent $r$-twin orientation. In addition, the crystal lattices display a continuous and large (up to $95^{\circ}$ ) synthetic rotation from the original twin orientation approximately about the bulk vorticity axis (Y-direction) (Fig. 8c). The majority of recrystallized grains are entirely surrounded by highangle boundaries with misorientations $>20^{\circ}$ (Fig. 9a), and the grains with the highest rotation away from the orientation of the parent twin do not show any preferred spatial distribution within the recrystallized band (Fig. 9b). Adjacent grains along the recrystallized band show a discontinuous and large scatter of misorientations up to $95^{\circ}$ (Fig. 9a, c). Misorientation angles considerably larger that $15^{\circ}$ are also encountered across high-angle boundaries delimiting rare isolated grains within the strongly polygonized areas (Fig. 9a, b).

The distribution of misorientation angles between neighbour pairs of recrystallized grains shows a peak at $60^{\circ}$ (Fig. 10a). Misorientations between $10^{\circ}$ and $40^{\circ}$ occur with higher frequency than expected for a random distribution, whereas misorientations greater that $65^{\circ}$ occurs with a minor frequency than the random distribution until they drop to zero beyond $95^{\circ}$. In crystal coordinates, misorientation axes for misorientations of $10^{\circ}-50^{\circ}$ show a weak clustering along a girdle approximately connecting the poles to $\{r\}$ and $\{z\}$, with a maximum close to $\{r\}$ 

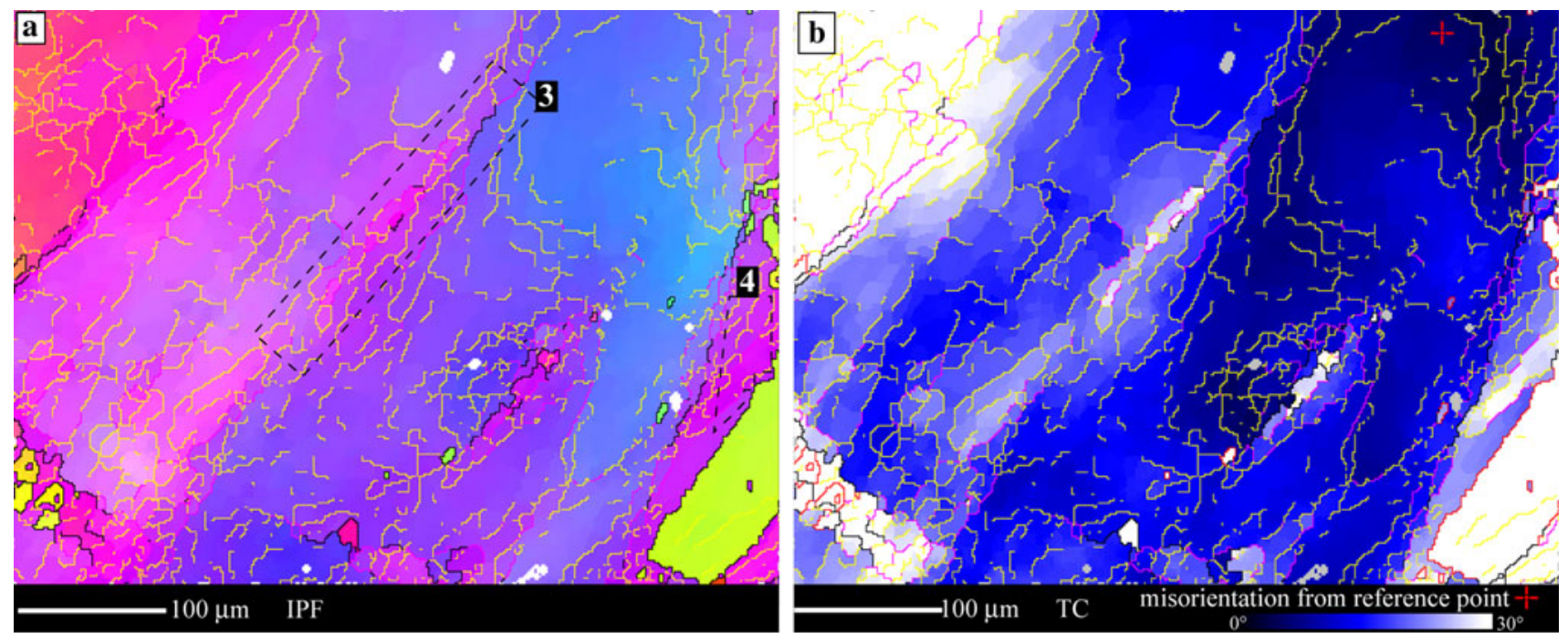

c

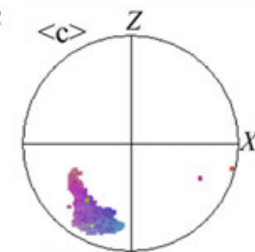

\{r\}

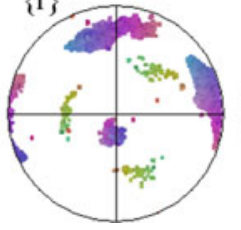

$\{\mathrm{z}\}$

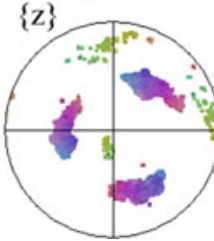

Fig. 5 a Processed EBSD Inverse Pole Figure (IPF) map of a region of porphyroclast A free of pervasive twinning (see Fig. 1b). Colour coding and boundaries as in Fig. 2a. White pixels are non-indexed points. Black dashed rectangles encompass the areas of sampling of datasets 3 and 4 for boundary trace analysis displayed in Fig. 6. b Processed EBSD Texture Component (TC) map of the same area as in (a). Grey pixels are non-indexed points. The map is colour-shaded

(Fig. 10b). Misorientation axes for misorientations of $50^{\circ}-$ $70^{\circ}$ have a strong maximum along the $c$-axis and a secondary maximum close to the pole to $\{\mathrm{r}\}$ (Fig. 10b). Misorientation axes for misorientations of $70^{\circ}-100^{\circ}$ show a strong maximum close to the pole to $\{r\}$ within a weak girdle connecting the poles to $\{\mathrm{r}\}$ and $\{\mathrm{z}\}$ (Fig. 10b). In sample coordinates, most of the misorientation axes between recrystallized grains for misorientations of $10^{\circ}-$ $50^{\circ}$ and $70^{\circ}-100^{\circ}$ are aligned close to the Y-direction of finite strain, i.e. to the bulk vorticity axis (Fig. 10c). Misorientation axes for misorientations of $50^{\circ}-70^{\circ}$ show a maximum inclined with a clockwise angle of about $40^{\circ}$ to the Z-direction (reflecting the dominant orientation of the $c$-axis of the recrystallized grains) and a secondary maximum parallel to the Y-direction (Fig. 10c).

The average size of the recrystallized grains is $10.9 \mu \mathrm{m}$ (Fig. 10d), similar to that of the subgrains in the
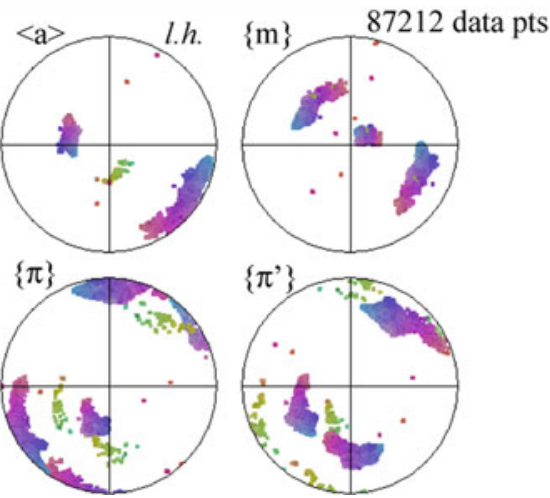

according to the angular misorientation from the reference point marked with a red cross. c Pole figures of the crystallographic orientation data of the data points in (a) and (b). Colour coding as in Fig. 5a. Upper hemisphere, equal angle stereographic projection. The orientation of the $<\mathrm{a}>$ axis is plotted on the upper hemisphere (u. h.) and on the lower hemisphere (1. h.) of the stereographic projection

polygonized areas. Recrystallized grains have an average aspect ratio of $1: 1.8$, and most of them exhibit low internal misorientation $\left(<2^{\circ}\right)$. A few large grains (size twice than average, see Fig. 8a) show internal misorientation between $4^{\circ}$ and $9^{\circ}$. Recrystallized grains exhibit no clear shape preferred orientation. According to the recrystallized grain size piezometer for quartz calibrated by Stipp and Tullis (2003), a grain size of $10.9 \mu \mathrm{m}$ yields a differential stress of $100 \mathrm{MPa}$.

\section{EBSD analysis of porphyroclasts B, C, D, E}

The IPF maps and pole figures of the porphyroclasts B-E (Fig. 1a) are presented in the electronic supplementary material. The primary aim of the analysis of four additional porphyroclasts is to increase the statistical information about the crystallographic orientation with respect to the 


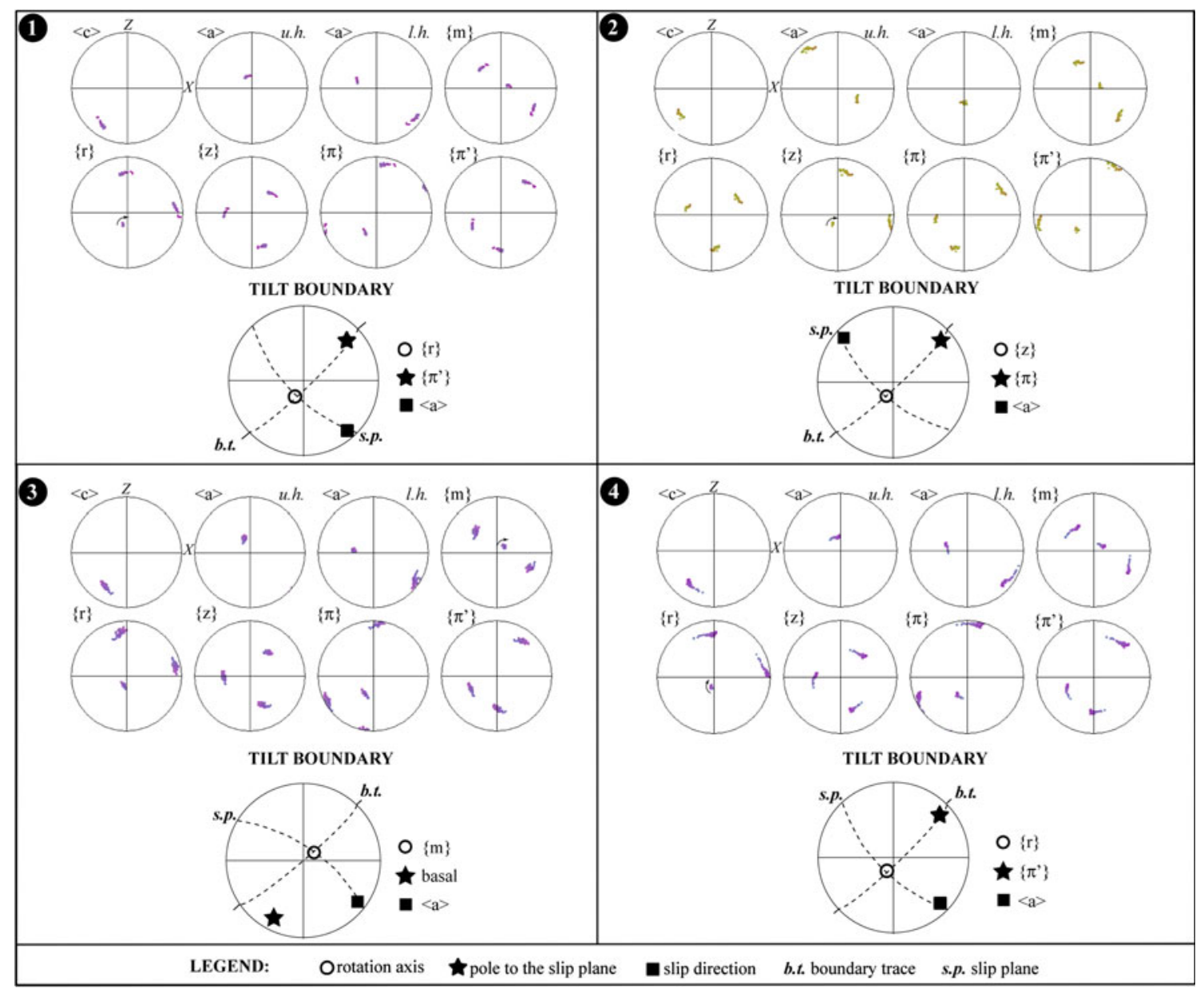

Fig. 6 Boundary trace analysis of four datasets representative of the most common geometries of low-angle boundaries in porphyroclast $\mathrm{A}$ (see Figs. 2a, 3 and 5 for location of datasets). Crystallographic data are plotted on the upper hemisphere of the equal angle stereographic projection. The orientation of the $<\mathrm{a}>$ axis is plotted on the upper hemisphere (u. h.) and on the lower hemisphere (l. h.) of the stereographic projection. Rotation axis is indicated in the pole figures. Colour coding as in Fig. 2a (datasets 1 and 2) and Fig. 5a (datasets 3 and 4). Our interpretation of the most feasible solution of the boundary trace analysis is sketched for each dataset. See text for further explanations

Table 1 Summary of results from boundary trace analysis of the most common low-angle boundaries observed in porphyroclast A

\begin{tabular}{llllll}
\hline Dataset & Host twin & Boundary orientation & Boundary type & Rotation axis & Slip system \\
\hline 1 & $r$-twin & $42-47^{\circ}$ to $\mathrm{Z}$ & tilt & $\{\mathrm{r}\}$ & $\left\{\pi^{\prime}\right\}<\mathrm{a}>$ \\
2 & $z$-twin & $41-48^{\circ}$ to Z & tilt & $\{\mathrm{z}\}$ & basal $<\mathrm{a}>$ \\
3 & $r$-twin & $44-47^{\circ}$ to Z & tilt & $\{\mathrm{r}\}$ & $\left\{\pi^{\prime}\right\}<\mathrm{a}>$ \\
4 & $r$-twin & $41-48^{\circ}$ to Z & tilt & \\
\hline
\end{tabular}

For location of datasets refer to Figs. 2a, 4 and 5. The average 2D orientation of the boundary trace is given as the clockwise angle with respect to Z-direction of finite strain. See text for explanation

maximum compressive axis in twinned and untwinned grains. The results are summarized in Table 2 .

Porphyroclasts $\mathrm{B}$ and $\mathrm{C}$ are oriented with one of the $\{\mathrm{r}\}$ planes nearly perpendicular to the maximum compressive axis. The pole figures and maps do not show any feature suggestive of the presence of Dauphiné twins. Porphyroclast $\mathrm{D}$ is oriented with one of the prismatic planes $\{\mathrm{m}\}$ nearly perpendicular to the maximum compressive axis and shows only a negligible development of Dauphiné twinning. On the contrary, Dauphiné twinning microstructures are pervasive in porphyroclast $\mathrm{E}$, which shows the superposition of the poles to the $\{r\}$ - and $\{z\}$-planes subparallel to the maximum compressive axis (supplementary material). 


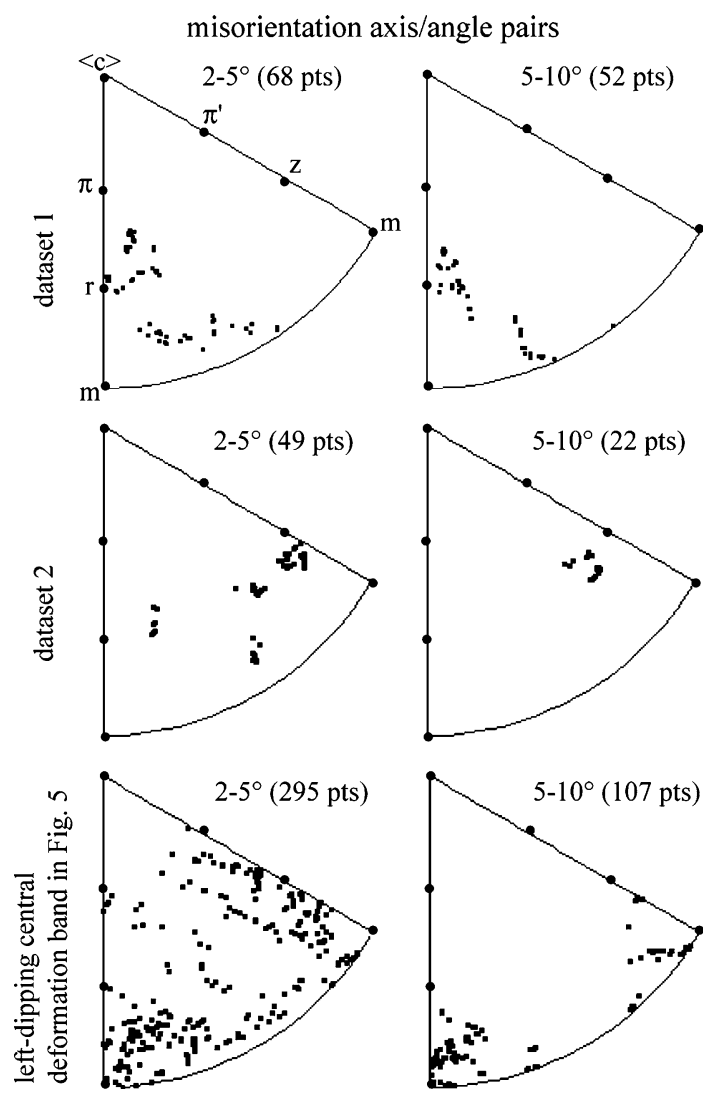

Fig. 7 Misorientation axis/angle pairs in crystal coordinates (inverse pole figure for quartz) for datasets 1,2 and for the central left-dipping deformation band shown in Fig. 5

\section{Discussion}

Formation of Dauphiné twins

The formation of mechanical Dauphiné twinning in quartz single crystals and/or polycrystalline aggregates has been subject of several experimental, theoretical and numerical studies (e.g. Tullis 1970; Tullis and Tullis 1972; Pehl and Wenk 2005; Wenk et al. 2006, 2007). A consistent result of these investigations is that twinning acts to align the direction of greater compliance parallel to the compression axis; therefore, the activation of the twinning process depends on the orientation of the crystal with respect to the applied stress. More specifically, under constant stress conditions, the driving force for Dauphiné twinning is the maximization of the elastic strain energy, a condition required for thermodynamic equilibrium (Tullis and Tullis 1972). Different from some twinning laws in other minerals (e.g. calcite, feldspars), no permanent strain is involved in Dauphiné twinning. Therefore, mechanical Dauphiné twinning cannot be considered a strain-accommodating mechanism, but rather a process reducing the stiffness of a crystal to make it more deformable (Tullis 1970; Tullis and Tullis 1972).
Elastic compliance in common rock-forming minerals is strongly anisotropic (De Vore 1970). In quartz, the maximum uniaxial compliance is nearly orthogonal to the positive rhombohedral planes $\{r\}$ and is about twice the minimum value, which is orthogonal to the negative rhombohedral planes $\{\mathrm{z}\}$ (McSkimin et al. 1965; Lloyd 2000). This is consistent with the experiments of Tullis (1970) and Tullis and Tullis (1972), where crystals loaded orthogonal to $\{\mathrm{z}\}$ changed their orientation by twinning. Sharp differences in the pole figures of $\{r\}$ and $\{z\}$, with the preferred alignment of the $\{r\}$ poles parallel to the compression axis, most likely as a result of mechanical twinning, have also been observed by Heidelbach et al. (2000), Lloyd (2000), Pehl and Wenk (2005), Wenk et al. (2006, 2007) and Stipp and Kunze (2008).

The porphyroclast A investigated in the present study shows (1) the superposition of one $\{r\}$ and one $\{z\}$ plane orthogonal to the maximum compressive axis (subparallel to Z) (Fig. 2b), (2) the preferential alignment of the poles of one $\{r\}$ plane parallel to the compressive axis in the regions free of a pervasive network of Dauphiné twin boundaries (such as the area shown in Fig. 5) and (3) the localization of much of the plastic strain in the $r$-twin (Fig. 2a). We infer that these observations indicate that the $z$-twin was the original grain orientation undergoing mechanical twinning during the incipient stages of deformation, in agreement with thermodynamic analysis and previous reports of Dauphiné twinning (Tullis 1970; Tullis and Tullis 1972; Pehl and Wenk 2005; Wenk et al. 2006, 2007). This is consistent with the microstructural interpretation that the maximum compressive axis for the quartz grains was in effect subparallel to $\mathrm{Z}$ in the Arolla sheared granitoids, where quartz behaved as a relatively strong phase experiencing dominantly coaxial deformation (Menegon et al. 2008).

Detailed EBSD analysis presented in table 2 and the electronic supplementary material support the interpretation that the $z$-twin orientation is the one most prone to undergo mechanical Dauphiné twinning. Analyses show (1) the lack of Dauphiné twinning on grains loaded orthogonal to one $\{r\}$ plane (porphyroclasts B and C), (2) a negligible development of twinning on a grain loaded orthogonal to one prism plane $\{\mathrm{m}\}$ (porphyroclast $\mathrm{D}$ ) and (3) again the extensive development of twinning on a grain loaded orthogonal to one negative rhombohedral plane $\{z\}$ (porphyroclast E). The superposition of the poles to $\{\mathrm{r}\}$ and $\{z\}$ is a result of twinning and occurs on grains loaded parallel to the $\{z\}$-plane normal (porphyroclasts $A$ and $E$ ), but not on grains loaded parallel to the $\{r\}$-plane normal (porphyroclasts B and C). The superposition of the poles to $\{r\}$ and $\{z\}$ indicates that twinning did not go into completion in those grains (porphyroclasts $\mathrm{A}$ and E). Grains in an $r$-twin orientation might in principle represent 


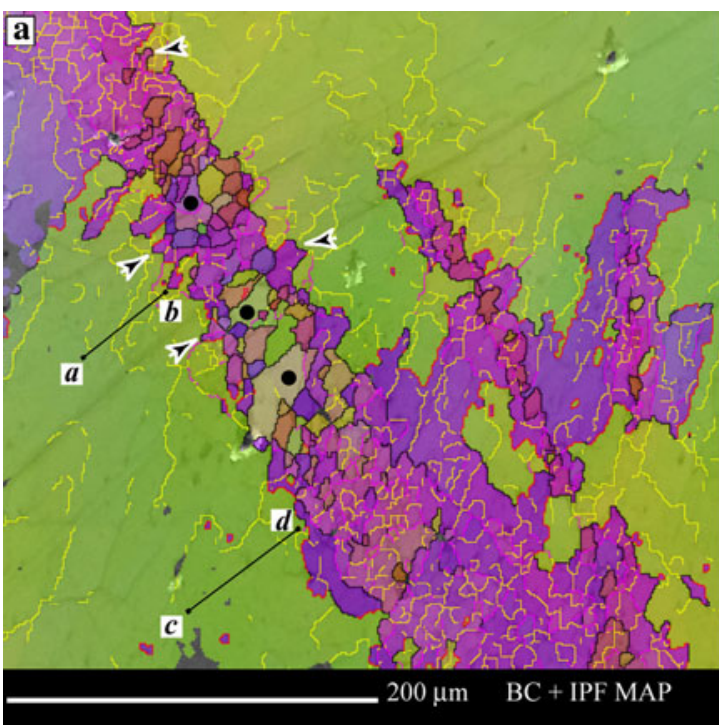

Fig. 8 a Processed EBSD BC + IPF map of the recrystallized grains and of the area of subgrain polygonization localized along an $r$-twin band. Colour coding and boundaries as in Fig. 2a. Arrowheads indicate local bulges of the $r$-twin bands in contact with the neighbouring $z$-twin. The size of bulges is similar to that of subgrains and recrystallized grains. Black dots indicate recrystallized grains with internal misorientation $>5^{\circ}$, as evidenced by the presence of low-angle boundaries. Black lines represent the locations of misorientation profiles $a-b$ and $c-d$ displayed in Fig. 8b. b Misorientation profiles $a-b$ and $c-d$ showing the change in orientation with respect to the starting point. Lattice distortion is higher in portions close to the recrystallized grains (profile $a-b$ ) with respect to
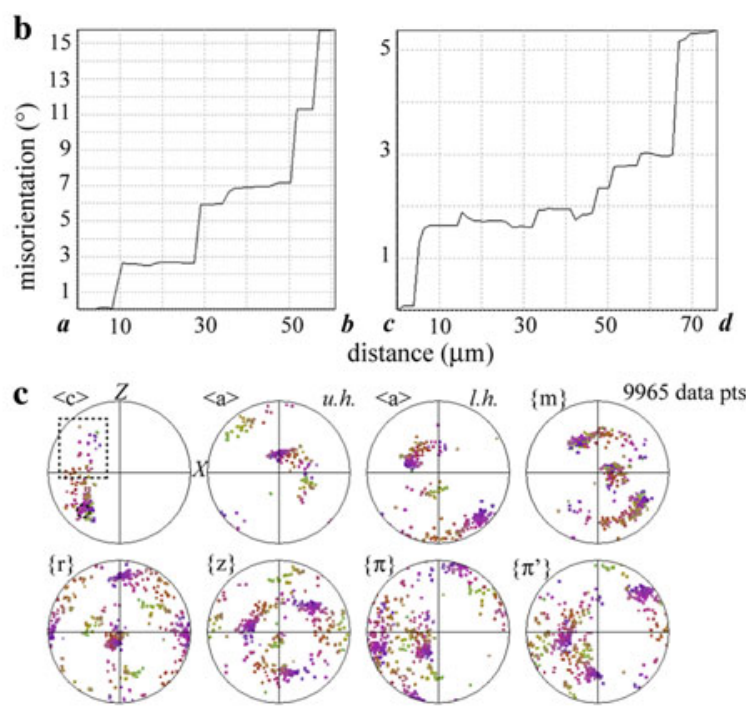

portions away from them (profile $c-d$ ). $\mathbf{c}$ Pole figures of the crystallographic orientation data of the recrystallized grains shown in (a). Colour coding like in Fig. 8a. The $c$-axis orientation of the parent $r$-twin is marked with a dashed black circle. Upper hemisphere, equal area projection. The orientation of the $<a>$ axis is plotted on the upper hemisphere (u. h.) and on the lower hemisphere (1.h.) of the stereographic projection. The dashed black rectangle encompasses the grains with the largest clockwise rotation away from the parent twin orientation. The distribution of these grains is shown in detail in the grain boundary misorientation map in Fig. 9b
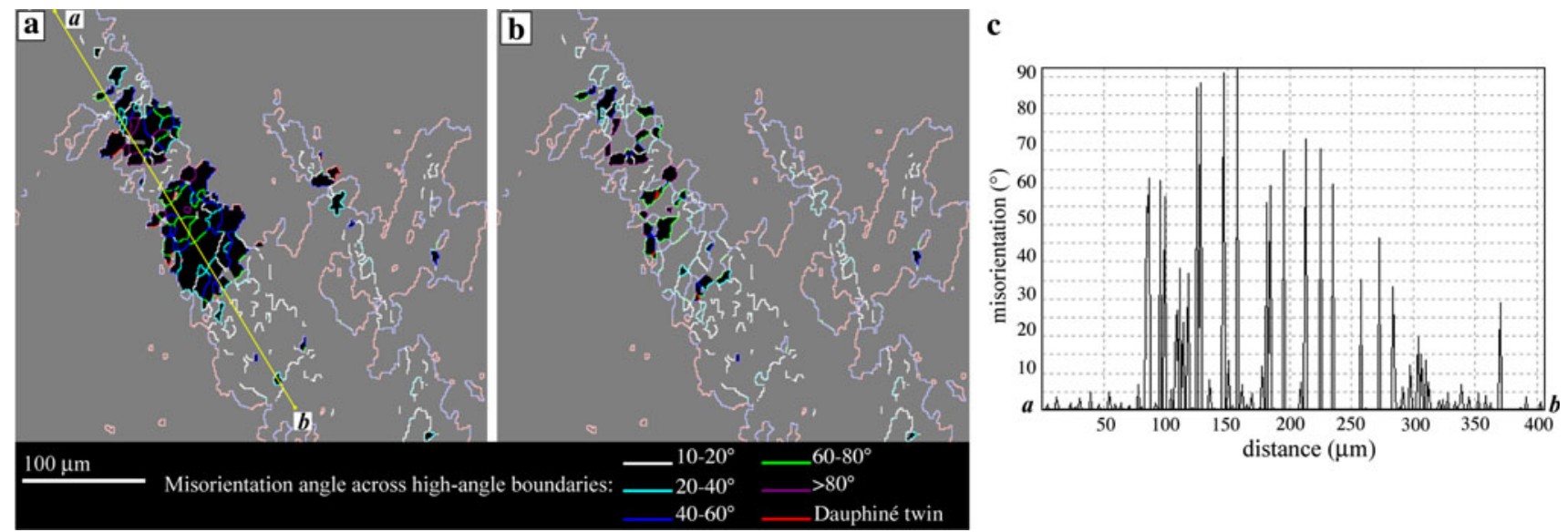

Fig. 9 a Grain boundary misorientation map of the recrystallized grains. Recrystallized grains are highlighted in black on a grey background. Key to colour code of the different boundary types is shown in the bottom. Yellow line represents the location of misorientation profile $a-b$ displayed in Fig. 9c. b Grain boundary misorientation map of the recrystallized grains with the largest

completely transformed grains, which actually did not twin further because they were in the most compliant orientation (porphyroclasts B and C) (Table 2).

Twinning is not a late feature in the deformation history of the Arolla porphyroclast A, as subgrains and clockwise rotation away from the parent twin orientation, encompassed in the black dashed rectangle in Fig. 8c. The majority of these grains is entirely surrounded by high-angle grain boundaries with misorientations $>20^{\circ}$. c Misorientation profile $a-b$ showing the pointto-point change in orientation

recrystallized grains are confined within an individual $r$-twin band (Fig. 8a). This is different from the microstructures observed by Heidelbach et al. (2000) in a quartzite from the Bergell Alps (Switzerland), indicating that twinning post-dated recrystallization given the lack of 


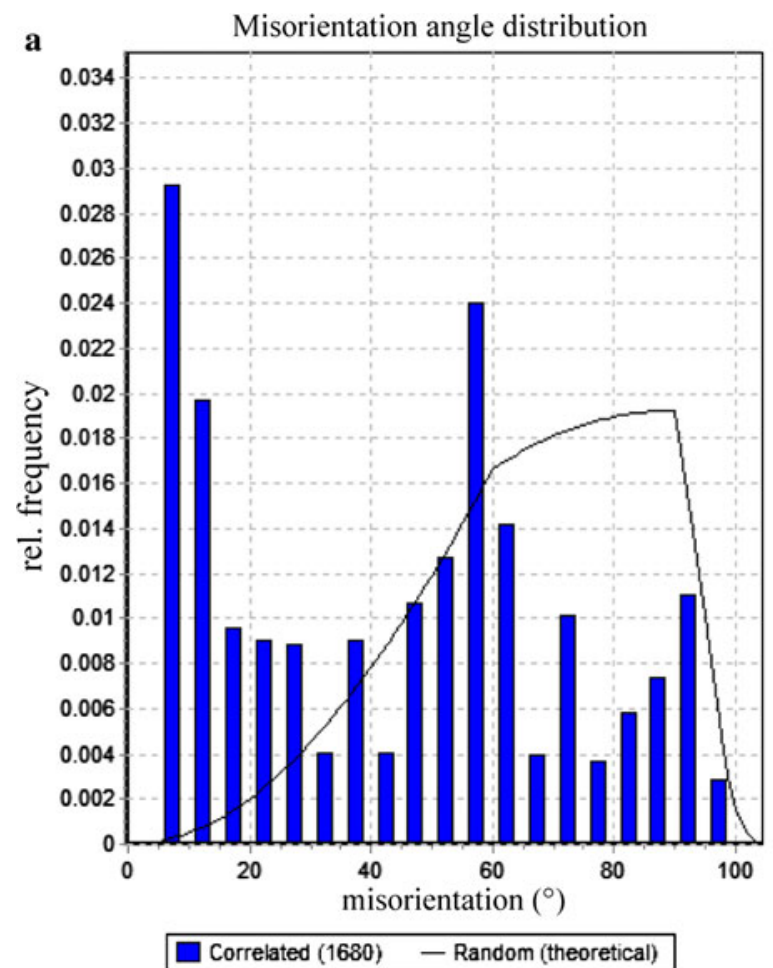

b

misorientation axis/angle pairs in crystal coordinates

$10-50^{\circ}(2373 \mathrm{pts}) \quad 50-70^{\circ}(5677 \mathrm{pts}) \quad 70-100^{\circ}(424 \mathrm{pts})$
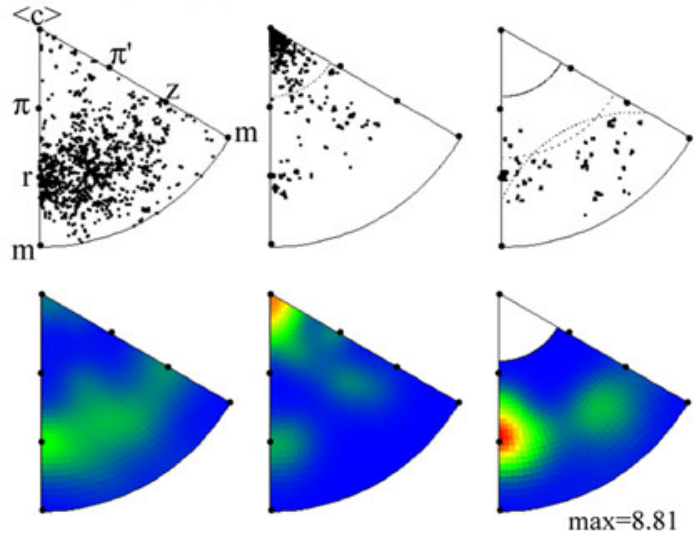

$\mathbf{c}_{\text {misorientation axis/angle pairs in sample coordinates }}$ $10-50^{\circ}(2373 \mathrm{pts}) \quad 50-70^{\circ}(5677 \mathrm{pts}) \quad 70-100^{\circ}(424 \mathrm{pts})$
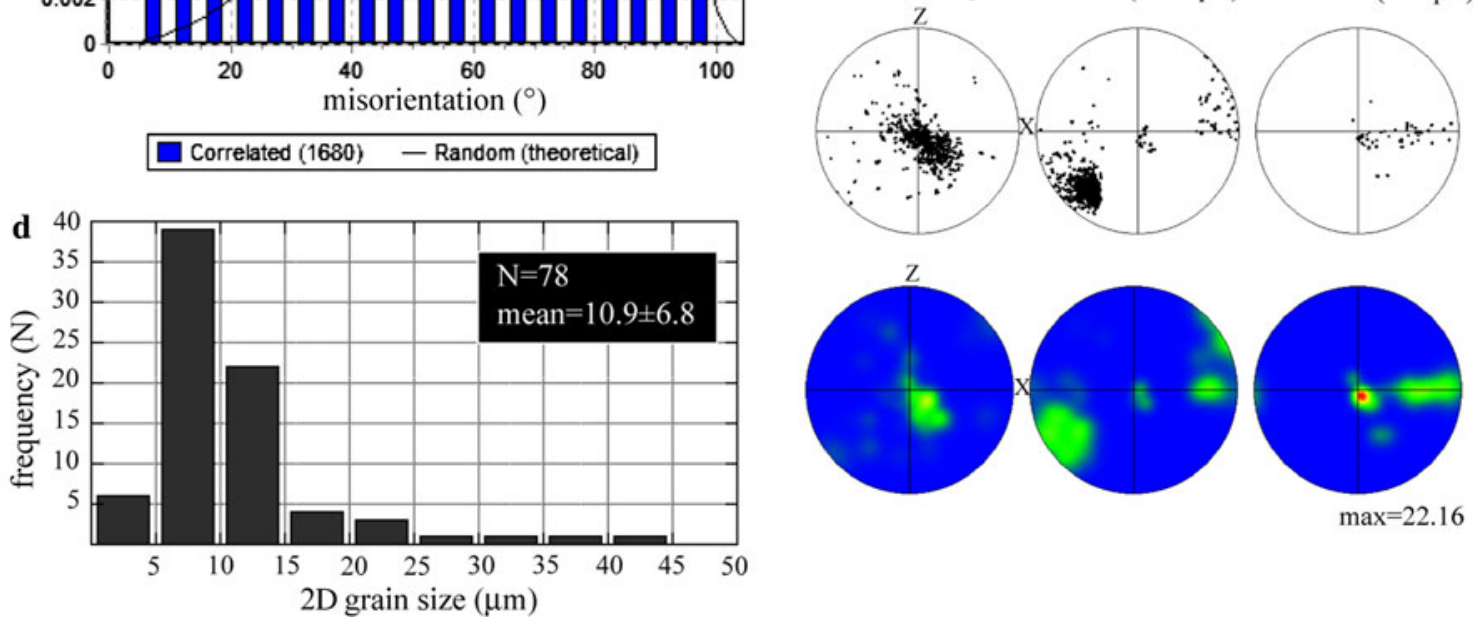

Fig. 10 a Histogram of distribution of misorientation angles between recrystallized grains. b Misorientation axis/angle pairs for the recrystallized grains. Data are plotted in crystal coordinates (inverse pole figure for quartz) and contoured (half width $20^{\circ}$ and cluster size $5^{\circ}$, maximum value is given). c Misorientation axis/angle pairs for the

Table 2 Summary of the relationships between the crystallographic orientations of the 5 analysed porphyroclasts with respect to the maximum compressive axis and the presence/absence of Dauphiné twinning (for pole figures and EBSD maps, the reader is referred to the Supplementary Material)

\begin{tabular}{lll}
\hline Porphyroclast & $\begin{array}{l}\text { Orientation of maximum } \\
\text { compressive axis }\end{array}$ & $\begin{array}{l}\text { Dauphiné } \\
\text { twinning }\end{array}$ \\
\hline $\mathrm{A}$ & $\begin{array}{l}\text { Orthogonal to one }\{\mathrm{z}\} \\
\text { and one }\{\mathrm{r}\} \text { plane }\end{array}$ & Yes \\
$\mathrm{B}$ & $\begin{array}{l}\text { Orthogonal to one }\{\mathrm{r}\} \text { plane } \\
\mathrm{C}\end{array}$ & No \\
$\mathrm{D}$ & Orthogonal to one $\{\mathrm{r}\}$ plane & No \\
$\mathrm{E}$ & Orthogonal to one $\{\mathrm{m}\}$ plane & Negligible \\
& Orthogonal to one $\{\mathrm{z}\}$ & Yes \\
\hline
\end{tabular}

recrystallized grains. Data are plotted in sample coordinates (X, Y and Z-directions of finite strain) and contoured (half width $20^{\circ}$ and cluster size $5^{\circ}$, maximum value is given). d Grain size distribution of the recrystallized grains. Number of grains $(\mathrm{N})$, mean grain size and standard deviation are given

recrystallized grains at the twin boundaries or within individual twinned crystals. The microstructure in the studied Arolla sample suggests that Dauphiné twinning occurred prior to dynamic recrystallization and presumably developed synkinematically to the main deformation given the optimal orientation of the porphyroclast A with respect to the inferred direction of maximum stress. The lack of twinning in porphyroclasts $\mathrm{B}$ and $\mathrm{C}$ (supplementary material), which were loaded parallel to the $\{r\}$-plane normal (very compliant crystallographic direction), further supports the interpretation of the synkinematic Dauphiné twin growth in porphyroclast A.

The occurrence of two sets of Dauphiné twin boundaries forming traces intersecting at $90^{\circ}$ (one parallel to the $c$-axis 
and one to the basal plane: Fig. 2a) reflects the two feasible ways to produce a $60^{\circ}$ rotation of the crystal lattice around the $c$-axis. In the conventional case, the Dauphiné twin plane is defined by a tilt boundary parallel to the prism plane (and to the $c$-axis). Lloyd (2004) postulated the existence of a second type of Dauphiné twin plane, defined by a twist boundary parallel to the basal plane (and therefore normal to the $c$-axis) (Figure 8 in Lloyd 2004). The porphyroclast A analysed in the present study indicates that both types of Dauphiné twin boundaries may actually form in one single grain.

The potential use of Dauphiné twinning as palaeopiezometer in quartz-bearing rocks has been extensively discussed in the literature (Tullis 1980; Pehl and Wenk 2005; Wenk et al. 2006). Experiments by Wenk et al. (2007) established the dependence of Dauphiné twinning on both stress and temperature; specifically, they reported the occurrence of twinning at about $100 \mathrm{MPa}$ at temperatures of $300-400^{\circ} \mathrm{C}$. In the Arolla samples, Dauphiné twinning was synkinematic to the incipient phase of deformation of the porphyroclast A, which occurred at $T$ of $300-400^{\circ} \mathrm{C}$, and therefore, a differential stress of about $100 \mathrm{MPa}$ should be required to initiate twinning if we extrapolate the experimental data of Wenk et al. (2007) to this natural example. The grain size piezometer for the recrystallized grains in porphyroclast A indicates a differential stress of $100 \mathrm{MPa}$ during dynamic recrystallization. The recrystallized grain sizes of quartz in the $r$-twin band and in high strain Arolla granitoid mylonites (where quartz recrystallization is pervasive) are of the same order (Menegon et al. 2008), indicating that recrystallized grain size did not change with increasing strain in the Arolla sheared granitoids. In addition, recrystallization is almost complete in the $r$-twin band, where the polygonized subgrains have the same size as the recrystallized grains. These observations indicate that the microstructure of the recrystallized $r$-twin band can reasonably be assumed to reflect local (at least) steady-state flow, allowing application of the recrystallized piezometer. Therefore, the comparison between the experimental data from Wenk et al. (2007) and the recrystallized grain size piezometer from the $r$-twin band suggests that mechanical Dauphiné twinning indeed represents a potential palaeopiezometer in quartz-bearing rocks, provided that the $\mathrm{T}$ of deformation is known with a certain confidence.

Distribution of plastic strain in the twinned porphyroclast

Both the $r$ - and the $z$-twins were overprinted by crystal plastic deformation, with the former showing twice the density of low-angle boundaries than the latter (Fig. 2a). The higher amount of plastic strain in the $r$-twin is probably related to thermodynamic reasons that also explain the mechanical twinning itself. The Dauphiné twinning acts to maximize the strain energy of the crystal, and the stable twin member is the one with the higher stored strain energy at constant stress conditions (Tullis and Tullis 1972). Up to a critical value of stored strain energy, a material behaves elastically and undergoes recoverable deformation. Above this critical value, permanent deformation due to plastic flow is seen. We infer that the plastic strain seen in the $r$-twin reflects the larger amount of elastic strain energy stored in the $r$-twin in comparison to the $z$-twin. In the $r$-twin, the critical yield strength was reached and plastic flow occurred. We speculate that the crystal regions with the highest uniaxial compliance ( $r$-twins), and therefore a higher stored elastic strain at constant stress, were likely to undergo plastic yield at lower differential stress than the less compliant $z$-twin regions.

Therefore, Dauphiné twinning predisposes to strain partitioning and localization within an initially homogeneous crystal. The condition for this to occur is that the crystal is suitably oriented for twinning, facing one of the \{z\} planes to the shortening direction. Precursory Dauphiné twinning provides an alternative explanation for the development of intracrystalline shear bands in quartz observed in naturally (Van Daalen et al. 1999; Vollbrecht et al. 1999) and experimentally (Vernooij et al. 2006a) deformed single crystals of quartz. These authors related the formation of shear bands and associated recrystallization to the initial development of shear microfractures in an orientation parallel to crystallographic rhomb planes.

The result of the different predisposition of the $r$ - and $z$ twins to yield plastically can be considered as a sort of "competence contrast" between the two twin members during progressive plastic deformation, with the $z$-twin and $r$-twin behaving as a relatively less deformable and more deformable objects, respectively. The possible effects of this different mechanical behaviour on the microstructural evolution of the porphyroclast are discussed in the next paragraph.

Influence of Dauphiné twinning on the activation of the dominant slip systems

Portions of porphyroclast A, containing a pervasive network of Dauphiné twin boundaries, show the dominant activity of $\{\pi\}<a>$ and $\left\{\pi^{\prime}\right\}<a>$ slip systems, in contrast to the basal $<\mathrm{a}>$ slip in untwinned regions (Fig. 6; Table 1). Under the greenschist facies $\left(T=300-400^{\circ} \mathrm{C}\right)$ conditions of deformation of the Arolla mylonites, basal $<a>$ is described as the most favoured slip system in quartz (e.g. Schmid and Casey 1986; Stipp et al. 2002). The activity of $\{\pi\}<\mathrm{a}>$ and $\left\{\pi^{\prime}\right\}<\mathrm{a}>$ as secondary slip 


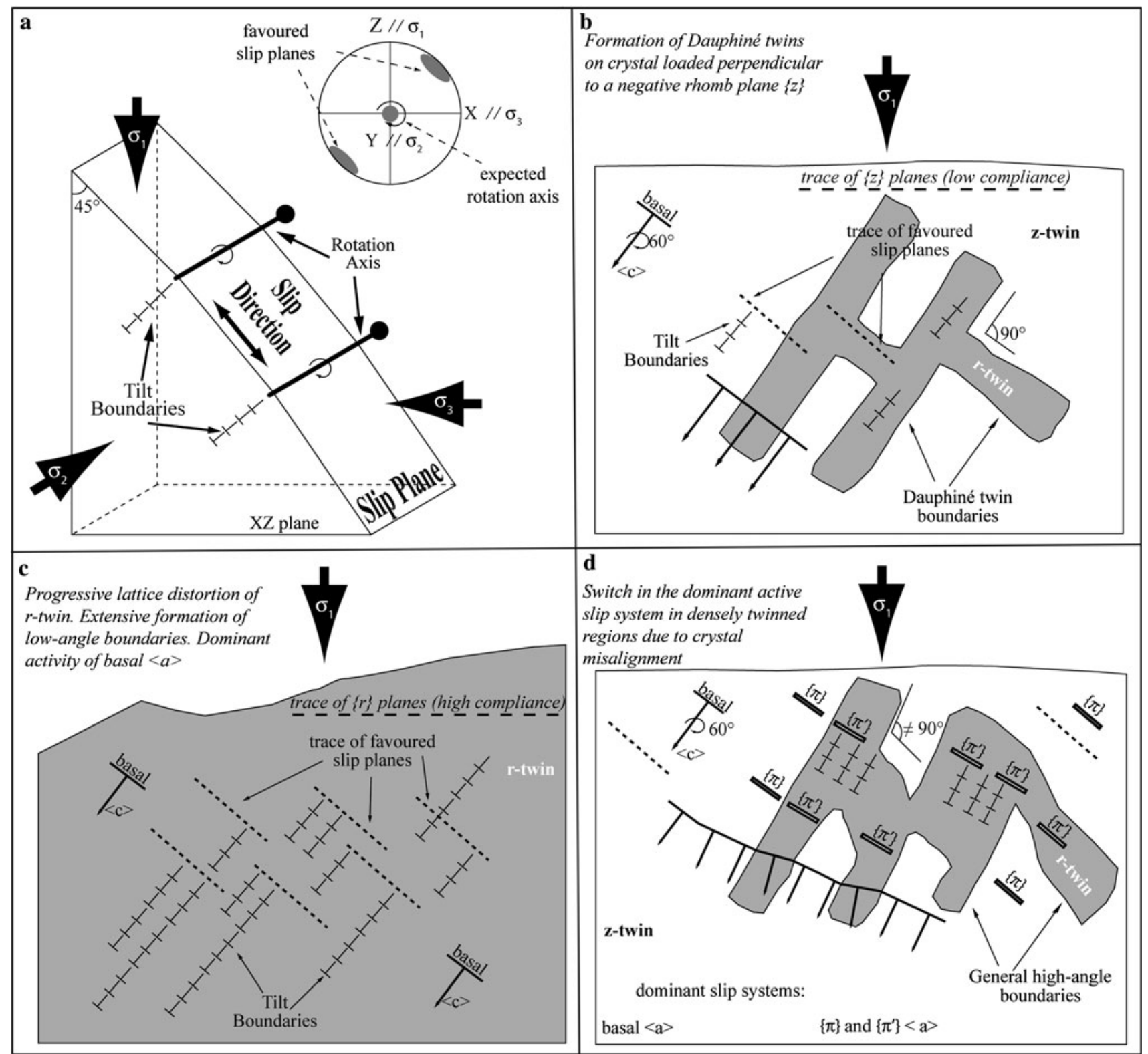

Fig. 11 Simplified schematic illustration of the evolution of Dauphiné twinning microstructure in porphyroclast A and of its influence on the switch in the dominant slip system. a Schematic illustration of the ideal orientation of slip plane and rotation axis when a crystal is loaded parallel to the Z-direction. For simplicity, the illustration is limited to the case of left-dipping low-angle boundaries formed by the activity of a right-dipping slip plane. b Mechanical Dauphiné twinning in a quartz grain oriented with the negative rhomb planes $\{z\}$ perpendicular to the loading direction. Two conjugate sets of $r$ twin symmetrically arranged with respect to the Z-direction are formed. Basal planes and $c$-axes of host and twin are perfectly aligned across the twin boundaries. c In the region outside the pervasive

systems has been reported in the literature (Schmid and Casey 1986; Law et al. 1990; Lloyd and Freeman 1994; Lloyd 2000, 2004; Stipp et al. 2002). It is worth to note that, in many of these cases, the quartz grains are affected by Dauphiné twinning (Law et al. 1990; Lloyd and twinning (with an $r$-twin orientation), the progressive lattice distortion is primarily accomplished by the activity of the slip system basal $<a>$ and leads to the formation of dominantly left-dipping tilt boundaries. Z-twins (not shown in this sketch) show less low-angle boundaries and a lower degree of lattice distortion. d As a result of the progressive lattice distortion of the $r$-twin, original twin boundaries are modified to general high-angle boundaries. Basal planes and $c$ axes are misaligned across what was originally a discrete twin boundary. Under these conditions, other geometrically favoured slip systems are activated in the pervasively twinned regions, such as $\{\pi\}$ and $\left\{\pi^{\prime}\right\}<a>$. Each twin member experiences a different microstructural evolution. See text for further details

Freeman 1994; Lloyd 2000, 2004). This possibly suggests that twinning exerts a control on the selection of the dominant slip system.

We suggest that once the twin boundary is formed, the $r$-twin and the $z$-twin behave differently during subsequent 
deformation and accumulate different amounts of intracrystalline strain through the activation of different slip systems. In case of a maximum compressive stress oriented parallel to $\mathrm{Z}$, the optimally oriented shear planes in the plastic field should lie at $45^{\circ}$ to $\mathrm{Z}$, and the rotation axis is expected to be close to Y (Fig. 11) (e.g. Barrie et al. 2008). In porphyroclast $\mathrm{A}$, the basal, the $\pi$ and the $\pi^{\prime}$ planes are all subparallel to planes of ideal orientation for shear activation (see Fig. 2b). Away from the twin boundaries, the plastic deformation of $r$-twin is accomplished by the dominant activity of the slip system basal $<a>$, with the accumulation of up to $25^{\circ}$ of internal lattice distortion (Fig. 5b). However, the $z$-twin is less prone to undergo plastic strain, and hence, due to the higher distortion of the crystal lattice in $r$-twin, the basal planes may have up to $25^{\circ}$ of misalignment across what was originally a discrete twin boundary (Fig. 5). Eventually, the twin boundary was modified to a general high-angle boundary and became a hindrance for the easy glide of dislocations along the misaligned basal plane. As a consequence, other favourably oriented slip systems are activated within individual twins. We cannot rule out that basal slip could have been active in the strongly polygonized regions of $r$-twin, but the higher distortion of the "soft" $r$-twin with respect to that of the "hard" $z$-twin apparently resulted in a switch in the dominant slip system within pervasively twinned regions of the porphyroclast (Fig. 11). Barrie et al. (2008) documented a similar switch in the active slip system in pyrite single crystals, due to crystal misalignment resulting from progressive lattice rotation. Furthermore, in regions of confined deformation between discrete twin boundaries, the activation of additional sets of slip systems (like $\{\pi\}$ $<\mathrm{a}>$ and $\left\{\pi^{\prime}\right\}<\mathrm{a}>$ ) conceivably allows compatibility problems to be overcome.

The fact that no continuous low-angle boundaries cut through twin boundaries further supports that each twin member experienced different microstructural modifications. The transformation of a Dauphiné twin boundary to a general high-angle boundary implies the loss of the pristine Dauphiné twin relation and most likely the misalignment of the $c$-axis in the two twin members. As Dauphiné twins are not detectable by optical microscopy, the $c$-axis misalignment accounts for the matching between some of the optically visible conjugate deformation bands (Fig. 1b) and the individual twin members identified by EBSD and OC (Figs. 2a, 3c).

In summary, our observations on porphyroclast $\mathrm{A}$ are consistent with a microstructural evolution including Dauphiné twinning during incipient stages of deformation. Ongoing distortion of the crystal lattice was preferentially localized within the $r$-twins and involved the activation of the basal $<\mathrm{a}>,\{\pi\}<\mathrm{a}>$ and $\left\{\pi^{\prime}\right\}<\mathrm{a}>$ slip systems, with the latter more favourably activated in regions with a pervasive network of twin boundaries. Progressive deformation resulted eventually in the development of low-angle boundaries and recrystallized grains overprinting the twins, with the local loss of the pristine Dauphiné twin crystallographic relation.

\section{Mechanism of dynamic recrystallization}

Dynamic recrystallization is localized along an $r$-twin and does not propagate into the $z$-twin. We propose that elongated Dauphiné twin bands act as preferred sites for dynamic recrystallization in quartz, as observed by Stipp and Kunze (2008) in both naturally and experimentally deformed samples. The localization of recrystallization along twins might also concur in developing the large misorientation typically observed at the boundary of many recrystallized shear bands in quartz (e.g. Vernooij et al. 2006b; Trepmann et al. 2007), as the accumulated lattice distortion modified the previous twin boundary to a general high-angle boundary.

The tight overlap in the pole figures between the individual maxima of recrystallized grains and the orientation of the host $r$-twin points to a major contribution of progressive subgrain rotation during dynamic recrystallization. This is also supported by the very similar size of subgrains and recrystallized grains. This latter observation suggests that the recrystallized grains did not undergo significant grain growth after grain size reduction. However, a local contribution of bulging recrystallization (Stipp et al. 2002; Stipp and Kunze 2008) is evidenced by the occurrence of bulges of the same size as subgrains and recrystallized grains in the $r$-twin band in contact to the neighbouring $z$-twin (Fig. 8a). Bulging recrystallization, as defined by Stipp and Kunze (2008), is a combined mechanism including the development of bulges by local slow grain boundary migration and of subgrain boundaries that finally cause the separation of new recrystallized grains when the subgrain rotation becomes large enough $\left(>10^{\circ}\right)$. Locally, the microstructure of recrystallized $r$-twin band in contact to the neighbouring $z$-twin supports this model.

Intracrystalline plasticity was the dominant deformation processes of the overall microstructure, as indicated by (1) the pervasive development of subgrains; (2) the local activity of slow grain boundary migration; and (3) the occurrence of a few grains, twice as large as the average recrystallized grain size, showing a higher internal misorientation (Fig. 8a): they possibly represent distorted portions of the host $r$-twin still undergoing grain size reduction through dynamic recrystallization. However, the continuous and large (up to $95^{\circ}$ ) clockwise (i.e. synthetic with the dextral sense of shear) rotation of some recrystallized grains away from the parent $r$-twin orientation 
cannot be attributed only to intracrystalline slip and lattice distortion. Grains with the largest rotation away from the parent twin orientation are entirely surrounded by very high-angle boundaries (Fig. 9b). We infer that the clockwise rotation path of some grains is consistent with a mechanism of rigid-body rotation about the bulk vorticity axis $\mathrm{Y}$ once the recrystallized grains are formed. This rotation was probably accommodated by grain boundary sliding, which concurred in the development of large misorientation angles between recrystallized grains (e.g. Jiang et al. 2000; Bestmann and Prior 2003). In numerical simple shear experiments, Bons and den Brok (2000) demonstrated that grains initially rotated over large angles $\left(>90^{\circ}\right)$ towards the fabric attractor and that this mechanism can be important in the development of a crystallographic preferred orientation. We cannot establish the amount of shear strain possibly accommodated by the band of recrystallized grains. However, portions of host grain flanking the recrystallized band show a higher lattice distortion, probably indicating that the array of recrystallized grains was indeed behaving as an intracrystalline shear zone.

Due to space problems, grain boundary sliding needs to be accommodated by different mechanism. We argue that the component of grain boundary sliding within the recrystallized $r$-twin band was most likely accommodated by dislocation glide (DisGBS: Warren and Hirth 2006, and references therein). In case of active DisGBS, Prior and Hirth (2007) suggested that misorientation axes between recrystallized grains would be primarily controlled by the deformation kinematics. In the light of this, and according to the model of Bons and den Brok (2000), the persistence of clusters of rotation axis along a girdle connecting $\{\mathrm{r}\}$ and $\{z\}$ even for high misorientations can be explained by these crystallographic directions being close to the bulk vorticity axis Y (Fig. 10b, c).

The peak at around $60^{\circ}$ in the misorientation angle distribution (Fig. 10a) is again indicative of the presence of Dauphiné twins in the recrystallized aggregate. They might have originated as growth twins during recrystallization or be inherited by the complex three-dimensional intergrowth of the twins that left isolated small portions of the host $z$-twin inside the $r$-twin (Fig. 2a).

In summary, the recrystallization microstructure and the crystallographic data are indicative of subgrain rotation as the dominant recrystallization mechanism, with a local contribution of bulging recrystallization. The recrystallized grains were confined in the discrete twin band and part of them, once formed, underwent rigid-body rotation around the bulk vorticity axis, which was accommodated by grain boundary sliding and accounts for the development of large misorientations angles.

\section{Conclusions}

Detailed EBSD analysis has shown that mechanical Dauphiné twinning extensively formed on a quartz porphyroclast in a greenschist facies $\left(T=300-400^{\circ} \mathrm{C}\right)$ granitoid protomylonites from the Arolla unit (North-western Italian Alps). Twinning developed synkinematically to the incipient stage of deformation and was triggered by the alignment of one of the stiff negative rhomb planes $\{\mathrm{z}\}$ perpendicular to the direction of maximum stress. This conclusion is supported by the lack of Dauphine twins on porphyroclasts loaded perpendicular to the more compliant positive rhomb planes $\{r\}$. As a result of twinning, portions of the original grain (z-twin orientation) aligned the $\{r\}$ plane normal parallel to the direction of maximum stress ( $r$-twin orientation). This is consistent with previous reports of mechanical Dauphiné twinning and confirms that it acts to align the planes with greater compliance perpendicular to the compression axis.

Our findings demonstrate that the presence of Dauphiné twins exerts a profound influence on (1) the partitioning and localization of plastic strain, (2) the selection of the dominant active slip system and (3) the localization of dynamic recrystallization. Much of the plastic strain of the twinned grain is localized in the $r$-twin, as a consequence of the higher amount of strain energy stored in this twin member resulting from the mechanical twinning. The progressive larger lattice distortion in the $r$-twin in comparison to the $z$-twin modified portions of the twin boundaries to general high-angle boundaries, across which the basal planes were misaligned. Crystal misalignment resulted in a switch in the dominant slip systems, from basal $<a>$ in region without twinning to $\{\pi\}<a>$ and $\left\{\pi^{\prime}\right\}$ $<$ a $>$ in regions with a pervasive network of twin boundaries. In regions of confined plastic deformation, such as the discrete $r$-twins, the additional activation of the $\{\pi\}$ $<\mathrm{a}>$ and $\left\{\pi^{\prime}\right\}<\mathrm{a}>$ slip systems could have concurred in overcoming compatibility problems.

Dynamic recrystallization is strictly localized along an $r$-twin band and occurred by progressive subgrain rotation, with a local contribution of bulging recrystallization. Once formed, some of the recrystallized grains underwent grain boundary sliding that accommodated large clockwise rotations of the crystallographic directions around the bulk vorticity axis. The grain size of dynamically recrystallized grains indicates differential stress of $100 \mathrm{MPa}$. This value is consistent with the development of Dauphiné twins in polycrystalline quartz experimentally loaded at $400^{\circ} \mathrm{C}$ by Wenk et al. (2007) and suggests that mechanical Dauphiné twinning has indeed a potential role as piezometer in quartz-bearing rocks. 
Acknowledgments This study has been funded by Padova University, Progetto Cariparo (Padova) and Stockholm University. Thorough and constructive reviews by C. Trepmann and M. Stipp are gratefully acknowledged. H. Stünitz and F. Nestola are thanked for discussions on deformation mechanisms and on quartz crystallography. S. P. thanks for financial support by the Swedish Research Council (VR 621-2004-5330), the Knut and Alice Wallenberg Foundation (financing of equipment) and the European Science Foundation (ESF) through their EUROCORES Programme EuroMinScl, FP6. M. Ahlbom and H. Solgevik are thanked for their help in SEM-based analyses.

Open Access This article is distributed under the terms of the Creative Commons Attribution Noncommercial License which permits any noncommercial use, distribution, and reproduction in any medium, provided the original author(s) and source are credited.

\section{References}

Adams BL, Wright SI, Kunze K (1992) Orientation imaging: the emergence of a new microscopy. Metall Trans A 24:819-831

Barrie CD, Boyle AP, Cox SF, Prior DJ (2008) Slip systems and critical resolved shear stress in pyrite: an electron backscatter diffraction (EBSD) investigation. Mineral Mag 72:1181-1199

Bestmann M, Prior DJ (2003) Intragranular dynamic recrystallization in naturally deformed calcite marble: diffusion accommodated grain boundary sliding as a result of subgrain rotation recrystallization. J Struct Geol 25:1597-1613

Bons PD, den Brok B (2000) Crystallographic preferred orientation development by dissolution-precipitation creep. J Struct Geol 22:1713-1722

Dal Piaz GV, Cortiana G, Del Moro A, Martin S, Pennacchioni G, Tartarotti P (2001) Tertiary age and paleostructural inferences of the eclogitic imprint in the Austroalpine outliers and Zermatt Saas ophiolite, western Alps. Int J Earth Sci 90:668-684

De Vore GW (1970) Elastic compliances of minerals related to crystallographic orientation and elastic strain energy relations in twinned crystals. Lithos 3:193-208

Fitz Gerald JD, Stünitz H (1993) Deformation of granitoids at low metamorphic grade. I: reactions and grain size reduction. Tectonophysics 221:269-297

Frondel C (1962) The system of mineralogy, 7th edn, vol III, silica minerals. Wiley, New York

Fynn GW, Powell WJA (1979) The cutting and polishing of electrooptic materials. Adams Hilger, London

Goodwin LB, Tikoff B (2002) Competency contrast, kinematics, and the development of foliations and lineations in the crust. J Struct Geol 24:1065-1085

Heidelbach F, Kunze K, Wenk H-R (2000) Texture analysis of a recrystallized quartzite using electron diffraction in the scanning electron microscope. J Struct Geol 22:91-104

Jiang Z, Prior DJ, Wheeler J (2000) Albite crystallographic preferred orientation and grain misorientation distribution in a low-grade mylonite: implications for granular flow. J Struct Geol 22:1663-1674

Law RD, Schmid SM, Wheeler J (1990) Simple shear deformation and quartz crystallographic fabrics: a possible natural example from the Torridon area of NW Scotland. J Struct Geol 12:29-45

Lister GS, Williams PF (1983) The partitioning of deformation in flowing rock masses. Tectonophysics 92:1-33

Lloyd GE (2000) Grain boundary contact effects during faulting of quartzite: an SEM/EBSD analysis. J Struct Geol 22:1675-1693
Lloyd GE (2004) Microstructural evolution in a mylonitic quartz simple shear zone: the significant roles of dauphine twinning and misorientation. In: Alsop GI, Holdsworth RE, McCaffrey KJW, Hand M (eds) Flow processes in faults and shear zones. Geological Society of London, Special Publication 224, pp 39-61

Lloyd GE, Freeman B (1994) Dynamic recrystallization of quartz under greenschist conditions. J Struct Geol 16:867-881

McSkimin HJ, Andreatch P, Thurston RN (1965) Elastic moduli of quartz versus hydrostatic pressure at $25^{\circ} \mathrm{C}$ and $-195.8^{\circ} \mathrm{C}$. J Appl Phys 36:1624-1632

Menegon L, Pennacchioni G, Heilbronner R, Pittarello L (2008) Evolution of quartz microstructure and c-axis crystallographic preferred orientation within ductilely deformed granitoids (Arolla Unit, Western Alps). J Struct Geol 30:1332-1347

Mørk MBE, Moen K (2007) Compaction microstructures in quartz grains and quartz cement in deeply buried reservoir sandstones using combined petrography and EBSD analysis. J Struct Geol 29:1843-1854

Neumann B (2000) Texture development of recrystallized quartz polycrystals unravelled by orientation and misorientation characteristics. J Struct Geol 22:1695-1711

Pehl J, Wenk H-R (2005) Evidence for regional Dauphiné twinning in quartz from the Santa Rosa mylonite zone in Southern California. A neutron diffraction study. J Struct Geol 27:1741-1749

Pennacchioni G, Guermani A (1993) The mylonites of the Austroalpine Dent Blanche nappe along the northwestern side of the Valpelline Valley (Italian Western Alps). Memorie di Scienze Geologiche 45:37-55

Piazolo S, Prior DJ, Holness MD (2005) The use of combined cathodoluminescence and EBSD analysis: a case study investigating grain boundary migration mechanisms in quartz. J Microsc 217:152-161

Piazolo S, Montagnat M, Blackford JR (2008) Sub-structure characterization of experimentally and naturally deformed ice using cryo-EBSD. J Microsc 230:509-519

Prior DJ (1999) Problems in determining the misorientation axes, for small angular misorientations, using electron backscatter diffraction in the SEM. J Microsc 195:217-225

Prior DJ, Hirth G (2007) Microstructural recognition of grain boundary sliding and its rheological implications. DRT conference abstract. Rendiconti della Società Geologica Italiana 5:187

Prior DJ, Trimby PW, Weber UD, Dingley DJ (1996) Orientation contrast imaging of microstructures in rocks using forescatter detectors in the scanning electron microscope. Mineral Mag 60:859-869

Prior DJ, Wheeler J, Peruzzo L, Spiess R, Storey C (2002) Some garnet microstructures: an illustration of the potential of orientation maps and misorientation analysis in microstructural studies. J Struct Geol 24:999-1011

Schmid SM, Casey M (1986) Complete fabric analysis of some commonly observed quartz [c]-axis patterns. In: Hobbs BE, Heard HC (eds) Mineral and rock deformation: laboratory studies. American Geophysical Union, Geophysical Monograph 36, pp 263-286

Stipp M, Kunze K (2008) Dynamic recrystallization near the brittleplastic transition in naturally and experimentally deformed quartz aggregates. Tectonophysics 448:77-97

Stipp M, Tullis J (2003) The recrystallized grain size piezometer for quartz. Geophys Res Lett 30:2088. doi:10.1029/2003GL018444

Stipp M, Stünitz H, Heilbronner R, Schmid SM (2002) The eastern Tonale fault zone: a 'natural laboratory' for crystal plastic deformation of quartz over a temperature range from 250 to $700^{\circ} \mathrm{C}$. J Struct Geol 24:1861-1884

Thomas LA, Wooster WA (1951) Piezocrescenze - the growth of Dauphiné twinning in quartz under stress. R Soc London Proc A 208:43-62 
Trepmann CA, Stöckhert B (2003) Quartz microstructures developed during non-steady state plastic flow at rapidly decaying stress and strain rate. J Struct Geol 25:2035-2051

Trepmann CA, Stöckhert B, Dorner D, Moghadam RH, Küster M, Röller K (2007) Simulating coseismic deformation of quartz in the middle crust and fabric evolution during postseismic stress relaxation-an experimental study. Tectonophysics 442:83-104

Trimby PW, Prior DJ, Wheeler J (1998) Grain boundary hierarchy development in a quartz mylonite. J Struct Geol 20:917-935

Tullis J (1970) Quartz: preferred orientation in rocks produced by Dauphiné twinning. Science 168:1342-1344

Tullis TE (1980) The use of mechanical twinning in minerals as a measure of shear stress magnitudes. J Geophys Res 85(B11): 6263-6268

Tullis J, Tullis T (1972) Preferred orientation of quartz produced by mechanical dauphiné twinning: thermodynamics and axial experiments. In: Heard HC, Borg IY, Carter NI, Raleigh CB (eds) Flow and fracture of rocks, Geophysical Monograph 16, American Geophysical Union, pp 67-82

Van Daalen M, Heilbronner R, Kunze K (1999) Orientation analysis of localized shear deformation in quartz fibres at the brittleductile transition. Tectonophysics 303:83-107

Vernooij MGC, Kunze K, Den Brok B (2006a) 'Brittle' shear zones in experimentally deformed quartz single crystals. J Struct Geol 28:1292-1306

Vernooij MGC, Den Brok B, Kunze K (2006b) Development of crystallographic preferred orientations by nucleation and growth of new grains in experimentally deformed quartz single crystals. Tectonophysics 427:35-53

Vollbrecht A, Stipp M, Olesen NØ (1999) Crystallographic orientation of microcracks in quartz and inferred deformation processes: a study on gneisses from the German Continental Deep Drilling Project (KTB). Tectonophysics 303:279-297

Warren JC, Hirth G (2006) Gran size sensitive deformation mechanisms in naturally deformed peridotites. Earth Planet Sci Lett 248:438-450

Wenk H-R, Lonardelli I, Vogel SC, Tullis J (2005) Dauphiné twinning as evidence for an impact origin of preferred orientation in quartzite: an example from Vredefort, South Africa. Geology 33:273-276

Wenk H-R, Rybacki E, Dresen G, Lonardelli I, Barton N, Franz H, Gonzalez G (2006) Dauphiné twinning and texture memory in polycrystalline quartz. Part 1: experimental deformation of novaculite. Phys Chem Mineral 33:667-676

Wenk H-R, Bortolotti M, Barton N, Oliver E, Brown D (2007) Dauphiné twinning and texture memory in polycrystalline quartz. Part 2: in situ neutron diffraction compression experiments. Phys Chem Mineral 34:599-607

Wheeler J, Prior DJ, Jiang Z, Spiess R, Trimby PW (2001) The petrological significance of misorientations between grains. Contrib Mineral Petrol 141:109-124 